\title{
Physiology, regulation and multifunctional activity of the gut wall: a rationale for multicompartmental modelling
}

\author{
A. Bannink ${ }^{1 *}$, J. Dijkstra ${ }^{2}$, S.-J. Koopmans ${ }^{1}$ and Z. Mroz ${ }^{1}$ \\ ${ }^{1}$ Wageningen University Research Centre, Animal Sciences Group, Department of Animal Production, \\ PO Box 65, 8200 AB Lelystad, The Netherlands \\ ${ }^{2}$ Wageningen University, Animal Nutrition Group, PO Box 338, 6700 AH Wageningen, The Netherlands
}

\begin{abstract}
A rationale is given for a modelling approach to identify the mechanisms involved in the functioning and metabolic activity of tissues in the wall of the gastrointestinal tract. Maintenance and productive functions are discussed and related to the distinct compartments of the gastrointestinal tract and the metabolic costs involved. Functions identified are: tissue turnover; tissue proliferation; ion transport; nutrient transport; secretions of digestive enzymes, mucus and immunoglobulins; production of immune cells. The major nutrients involved include glucose, amino acids and volatile fatty acids. In vivo measurements of net portal fluxes of these nutrients in pigs and ruminants are evaluated to illustrate the complexity of physiology and metabolic activity of the gastrointestinal tract. Experimental evidence indicates that high, but variable and specific, nutrient costs are involved in the functioning of the gastrointestinal tract.
\end{abstract}

Multicompartmental modelling: Gastrointestinal tract: Nutrient metabolism

\section{Introduction}

Tissues in the gastrointestinal tract (GIT) wall (GIW) have a relatively high metabolic activity compared with other body tissues. This activity becomes apparent as a much higher contribution of the GIT to total heat production by the animal than the contribution of the GIT to total body weight (Huntington \& Reynolds, 1987). Compared with protein in skeletal muscle, the fractional protein synthesis rate (FPSR) and rate of protein degradation in the GIT is far higher (Nieto \& Lobley, 1999). Therefore, the supply of nutrients to the animal via the portal vein is determined to an important extent by the nutrient utilisation by the GIT in both ruminants and single-stomached animals. This implies that GIT metabolism affects the supply of individual nutrients to the peripheral organs of the animal.

The high rate of metabolic activity is accompanied by the utilisation of large quantities of nutrients. Nutrient supply from both the lumen of the GIT and from arterial blood shows large within-day fluctuations and depends on feeding strategy. Besides a nutritive role of the GIT, it also has an important function as a barrier and defence against damaging influences from the external environment of the animal. In addition, the presence of the endemic non-pathogenic microflora exerts an influence on the functioning of tissues in the GIW (Gaskins, 2003). Consequently, the metabolic activity of the GIT is strongly related to the nutritional, the microbial as well as the health status of the animal. Finally, measurement of nutrient utilisation by the GIW is limited to nutrient fluxes in arterial and portal blood, reflecting whole GIT metabolism. However, such measurements do not provide quantitative information on the separate, highly specialised GIT compartments.

The aim of the present review is to present an overview of the basic characteristics and variation in nutrient utilisation by the GIW and to relate this to its physiological functions in farm animals. A rationale is given for a modelling approach to identify and quantify the mechanisms involved in the metabolic activity of the GIW. Although there is a strong interaction between metabolic activity of the GIW and the metabolic processes taking place in the lumen, the latter is not a main subject of the present review. Because nutrient fluxes in portal blood reveal not only the outcome of digestive processes but also that of the (regulation of) physiological functions and nutrient metabolism of the GIW, the present paper includes a review of in vivo observations of these fluxes.

\footnotetext{
Abbreviations: AA, amino acid; EAA, essential amino acid; FPSR, fractional protein synthesis rate; GIT, gastrointestinal tract; GIW, gastrointestinal wall; LI, large intestine; NEAA, non-essential amino acid; PDV, portal-drained viscera; SI, small intestine; VFA, volatile fatty acid.

* Corresponding author: Dr André Bannink, fax +31 237320, email andre.bannink@wur.nl
} 


\section{A modelling approach of nutrient metabolism by the gastrointestinal tract}

Modelling of nutrient utilisation by the GIT requires that the metabolic processes and physiological functions of this organ be represented explicitly. A modelling approach may aid in the compartmentalisation of factors and physiological mechanisms involved in variation of nutrient utilisation by the GIW.

\section{Gastrointestinal tract compartmentalisation}

There are several levels of organisation of the GIT (Fig. 1). First, there is a morphological compartmentalisation of the GIT, not only determined by anatomy but also by biochemical and physiological characteristics. This compartmentalisation is related to the type of digestion taking place in the lumen and the supporting functions of the GIT. For the present review, a distinction between stomach (and the reticulo-rumen in the case of ruminants), the small intestine (SI) and the large intestine (LI) is required. Second, the GIT is composed of several tissue or cell types with highly specialised functions (Fig. 2). Various compartments include: (1) epithelium that forms the barrier between the internal and external milieu of the animal and simultaneously executes the functions of transport and absorption of nutrients from the lumen to the blood; (2) enzymesecreting cells; (3) mucus-secreting cells; (4) intra-epithelial lymphocytes and immune cells; (5) nervous system; (6) smooth muscle; (7) connective tissue between epithelia and smooth muscle layer. Third, a compartmentalisation can be made according to the individual metabolic functions which ensure a relatively constant intracellular environment and the integrity and optimal functioning of the tissues or cells. Functions that may be distinguished include active or facilitated transport of ions and nutrients, proliferation and breakdown of tissues and cells, and other functions for general cell maintenance. In addition, several productive functions can be distinguished, characterised by the synthesis of enzymes, mucus, immune secretions (for example, immunoglobulins), and cell components. Finally, there is a compartmentalisation on a biochemical level that distinguishes individual nutrients and biochemical pathways. This compartmentalisation involves nutrients utilised by the cells (glucose, acetate, propionate, butyrate, essential amino acids (EAA), non-essential amino acids (NEAA), and marginally long-chain fatty acids and TAG; Britton \& Krehbiel, 1993), metabolites formed (for example, $\beta$-OH-butyrate, lactate), ATP and NADH as units of metabolic energy and reducing power, and respiratory gases (for example, $\mathrm{O}_{2}, \mathrm{CO}_{2}$ ).

\section{Assumptions and simplifications}

Models of nutrient metabolism in organs usually assume that the organ is composed of a single standard cell or tissue type, and energy costs for supporting tissues are lumped into a single maintenance value. This simplification seems justified if the metabolic activity of epithelia dominates the total nutrient utilisation by the GIW. If other tissue types become metabolically more important and vary with dietary or health status, a more detailed representation is required. In the present review, the concept of a standard GIW cell type is used to discuss nutrient metabolism by the GIW, with nutrient supply from the lumen and from arterial blood as driving variables. We consider the various physiological functions of the GIT as a response of these standard cell types, with a variety of nutritional, animal and environmental factors influencing them as independent inputs. This means that a distinction is made between nutrient supply and the physiological state of the GIW as model inputs, the representation of the biochemical pathways of nutrient metabolism as the mechanism described by the model, and nutrient transport to blood as the outcome of the model.

\section{Representing gastrointestinal wall metabolism}

Fig. 3 depicts the relationship between model inputs (influencing factors and nutrient supply to the GIW) and model ouputs (nutrient supply to the animal and GIW nutrient metabolism) at several levels of organisation: animal, GIT and GIW. This distinction helps to reconsider the factors influencing GIT functioning and GIW metabolism.

Level represented

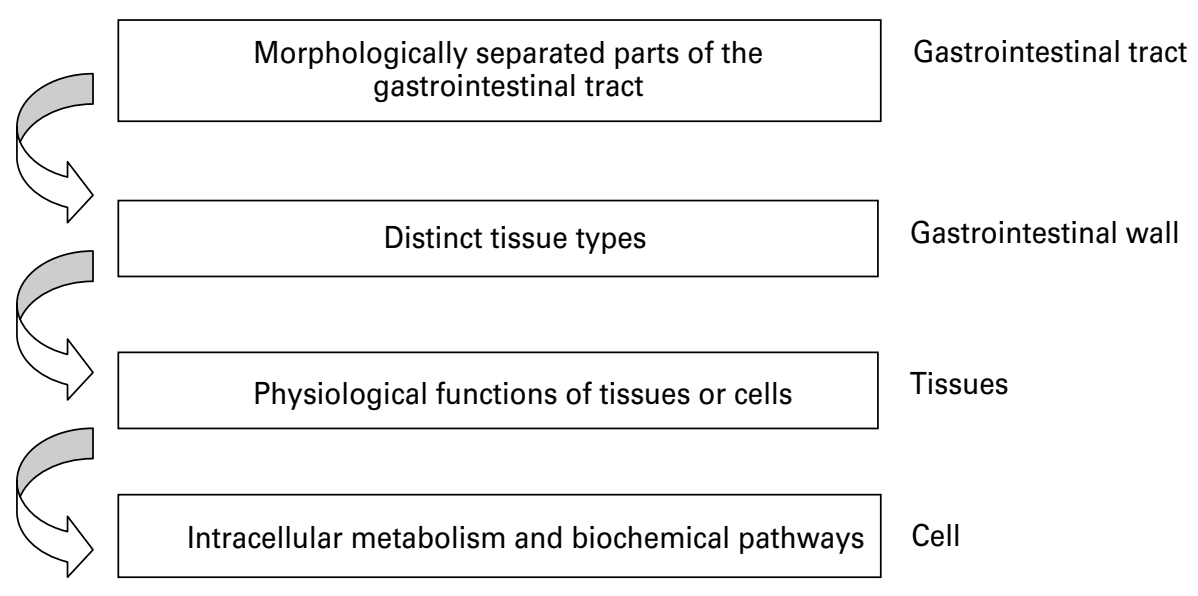

Fig. 1. Different levels of organisation in relation to representing nutrient metabolism by tissues of the gastrointestinal wall. 
Lamina propria Epithelium Mucus

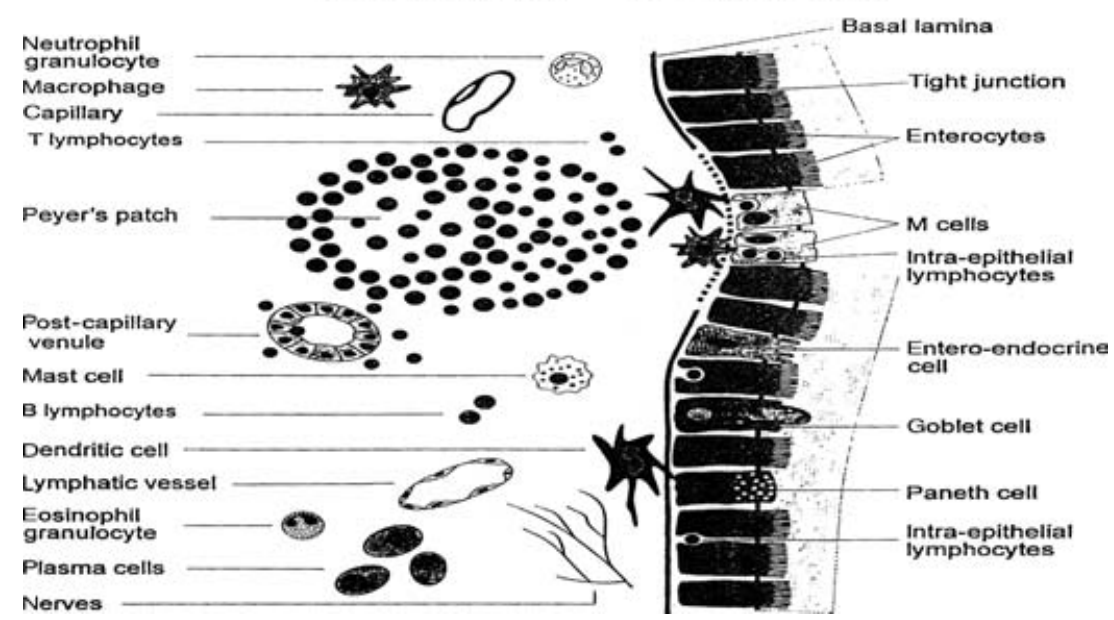

Fig. 2. Schematic representation of distinct cell types in the intestinal mucosa (derived from Pabst \& Rothkötter, 1998).

When compartmentalisation of the GIW is added, the scheme changes into that of Fig. 7 with an anatomical compartmentalisation of GIW included, and into Fig. 4 with compartmentalisation of physiological functions (tissue types) and biochemical pathways. The present study aims at a compartmentalised representation of GIW metabolism according to the organisation of influencing factors, functions and processes, and GIW nutrient utilisation and nutrient supply to the animal, according to both Figs. 4 and 7.

Similar principles hold for the representation of the metabolic activity of every type of tissue or cell, with glycolysis and the citric acid cycle as basic elements. Depending on the type of tissue or cell involved, different characteristics can be attributed to these pathways (enzyme kinetics, protein functions, and quantity, type and location of enzymes and proteins). In line with previous modelling efforts (for examples, see Baldwin, 1995; Dijkstra et al. 2005), a schematic representation of the metabolism of the GIW is illustrated in Fig. 4 (B), which represents mechanisms of nutrient transport, biochemical pathways, nutrient conversions and productive functions. Productive functions particularly involve the synthesis of protein, glycoproteins, nucleic acids and (phospho)lipids. Besides the incorporation of nutrients as a monomer for synthesis of cells and cell products, nutrients also become oxidised to deliver the ATP and NADH required to sustain these productive functions and

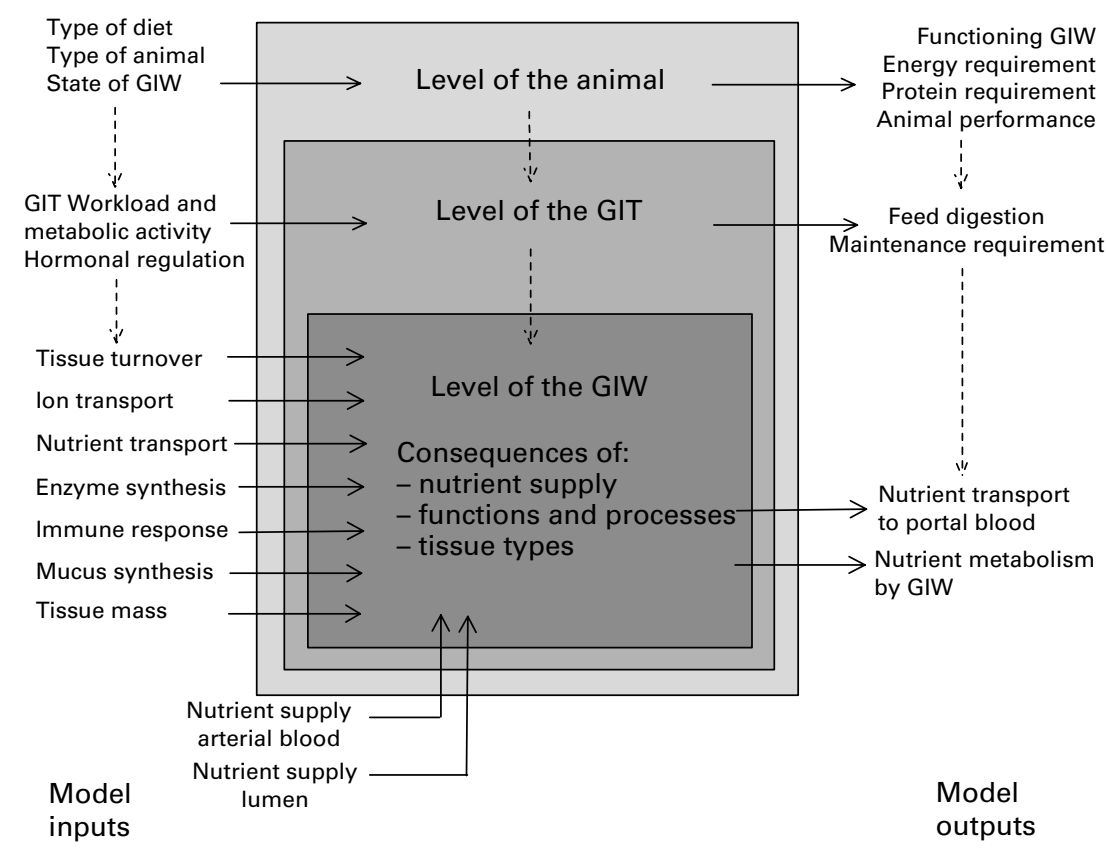

Fig. 3. Schematic representation of the modelling approach at different levels of organisation: the animal, the gastrointestinal tract (GIT) and tissue of the gastrointesinal wall (GIW). A distinction is proposed between model input being nutrient inputs and parameters for the physiological state of the GIT and its productive functions; model representation being the intracellular biochemical pathways of nutrient utilisation, and model output being the nutrient supply to portal blood and apparent nutrient utilisation by the GIW. 
(A)

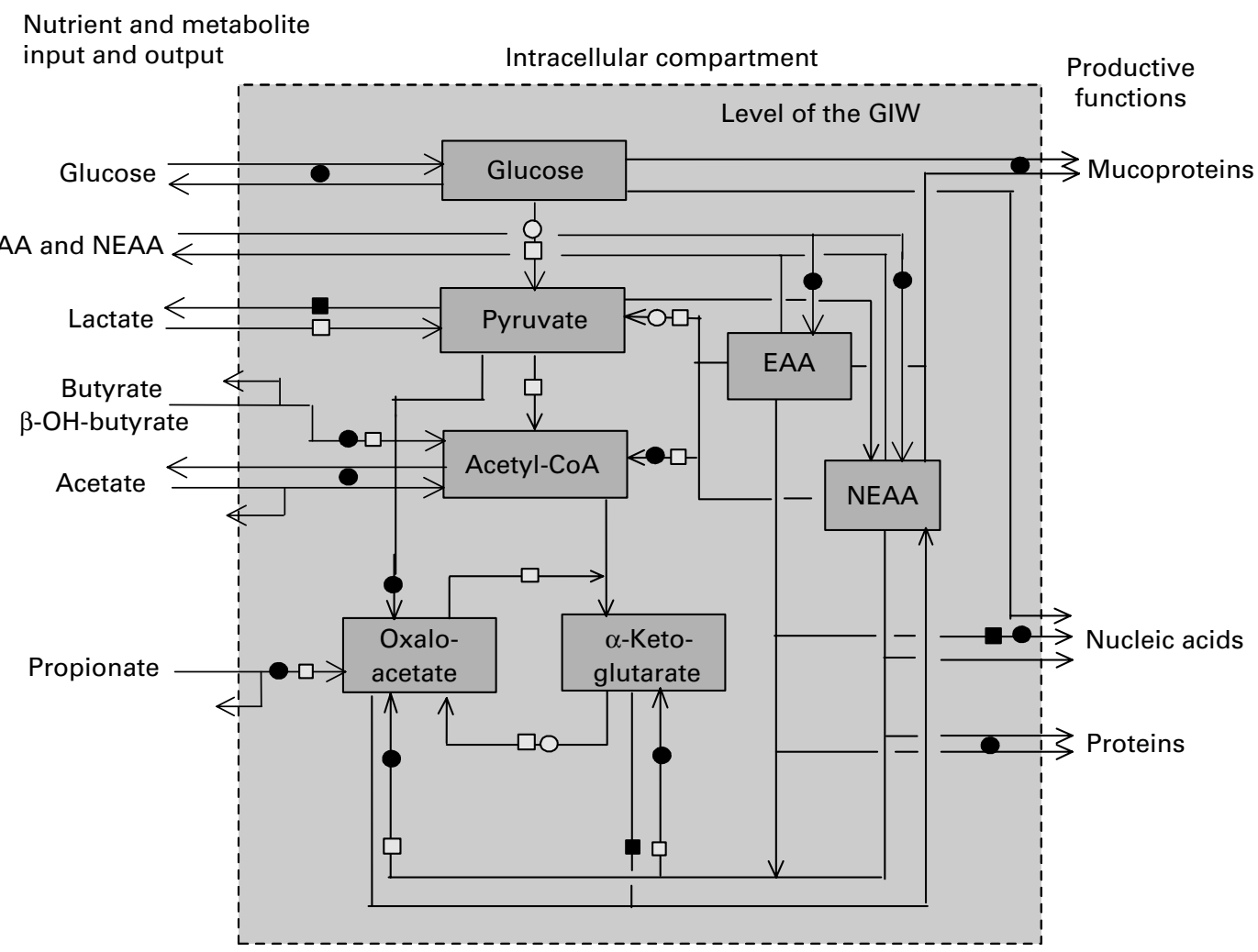

(B) Model Model

inputs

outputs

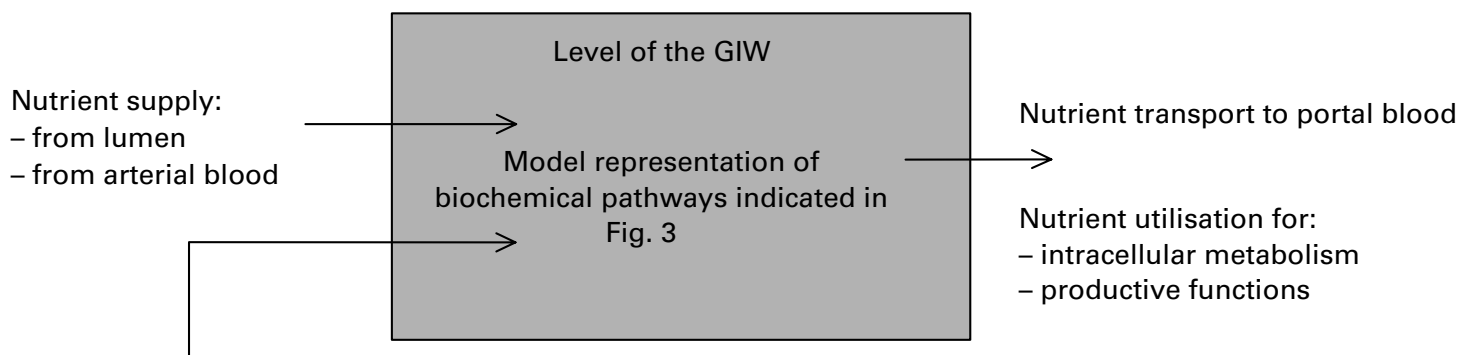

Physiological functions and processes of the GIW

Rates of productive functions of the GIW

Fig. 4. Schematic representation of the modelling approach to explain nutrient metabolism (A) from intracellular biochemical pathways of nutrient utilisation, and (B) as a function of nutrient supply and physiological functions of tissues of the gastrointestinal wall (GIW). In (A) thick lines indicate nutrient inputs and outputs; thin lines indicate intracellular metabolism and productive functions; boxes indicate intracellular pools of nutrients and metabolites; productive functions are indicated which are involved with tissue turnover, tissue growth and proliferation, secretions and the immune response. EAA, essential amino acids; NEAA, non-essential amino acids; (O), ATP production; $(\bullet)$, ATP utilisation; ( $\square$ ), NADH and $\mathrm{H}^{+}$production; $(\square), \mathrm{NADH}$ and $\mathrm{H}^{+}$utilisation. For details on the distinction between model inputs, model representation and model outputs, see Fig. 3.

to maintain the basic physiological functions of cells. For sound representation, rates of formation and utilisation of both ATP and NADH need to be in balance.

\section{Effect of metabolite concentrations on metabolic processes}

Variation in the extent of utilisation of specific nutrients finds its origin in known biochemical pathways. An example is the explanation of the stimulatory effect of propionate and glucose supply on the conversion of butyrate to $\beta-\mathrm{OH}-$ butyrate by rumen epithelia in vitro (Rémond et al. 1995;
Baldwin \& Jesse, 1996), which seems in line with in vivo observations on the effect of propionate and glucose on net portal fluxes (Gross et al. 1990b; Krehbiel et al. 1992; Seal \& Parker, 1994). Principles required for representation of these processes include:

concentration gradients (between lumen, arterial blood and mucosa) and (facilitated) transport mechanisms affect nutrient transport;

enzymic processes underlying nutrient metabolism depend on intracellular nutrient concentrations; 
changes in intracellular nutrient concentrations not necessarily reflecting nutrient transport rates;

a single intracellular compartment may be an oversimplification with the possibility of separate sources (lumen, arterial blood) and cell compartments causing separate routes of transport and metabolism.

From these principles two conclusions can be drawn. First, changes in nutrient supply from both luminal and arterial sources (in units of mass per unit time) are not necessarily related directly to changes in intracellular and extracellular nutrient concentrations (in units of mass per unit volume). Second, the mechanisms involved have to be represented to be able to relate the supply and intracellular concentration of nutrients to their metabolism.

\section{Mathematical representation}

Nutrient metabolism is an enzymically driven process which can be represented by a description of the enzyme kinetics involved. Separate kinetics are to be represented for the synthetic processes, with the incorporation of nutrients as monomers, and for the oxidation of nutrients to generate ATP and NADH (Fig. 4). Kinetics is specific for the type of nutrient, the type of tissue cells and the physiological state of this tissue. The rate of the enzymically driven process of utilisation of a nutrient depends on the concentration of this nutrient in the metabolic compartment under consideration. This concentration, $\mathrm{C}_{\mathrm{Nutr}}(\mathrm{mol} / \mathrm{l})$, is calculated from the quantity of nutrient $\left(\mathrm{Q}_{\text {Nutr }} ; \mathrm{mol}\right)$ present in the intracellular compartment of the GIW tissue involved and the fraction of intracellular metabolic volume $\left(f_{\text {metvol }}\right)$ of tissue mass (normally about $0 \cdot 8$ ). The following equations apply then for the calculation of $\mathrm{C}_{\mathrm{Nutr}}$ and the rate of nutrient utilisation $\left(\mathrm{U}_{\mathrm{Nutr}} ; \mathrm{mol} / \mathrm{d}\right)$ :

$\mathrm{C}_{\text {Nutr }}=\mathrm{Q}_{\text {Nutr }} /\left(\mathrm{Q}_{\text {Tissue }} \times \mathrm{f}_{\text {metvol }}\right)$,

$\mathrm{U}_{\text {Nutr }}=\mathrm{v}_{\max , \text { Nutr }} /\left(1+\mathrm{M} / \mathrm{C}_{\text {Nutr }}\right)$,

where $\mathrm{v}_{\text {max,Nutr }}$ is the maximum rate of nutrient utilisation (mol/d) and $\mathrm{M}$ is the affinity constant of nutrient utilisation $(\mathrm{mol} / \mathrm{l})$.

The effect of the mass of metabolically active tissue involved $\left(\mathrm{Q}_{\text {Tissue }} ; \mathrm{g}\right)$ on the nutrient utilisation capacity is represented by expressing $\mathrm{v}_{\max , \text { Nutr }}$ per unit tissue mass $(\mathrm{mol} / \mathrm{g}$ tissue per $\mathrm{d})$ :

$\mathrm{U}_{\text {Nutr }}=\left(\mathrm{v}_{\text {max }, \text { Nutr }} \times \mathrm{Q}_{\text {Tissue }}\right) /\left(1+\mathrm{M} / \mathrm{C}_{\text {Nutr }}\right)$.

With this type of equation the metabolism of all nutrient types can be represented. In the case of nutrient interactions, such as the competitive inhibition between two nutrients Nutr1 and Nutr2, the following type of equation can be used to describe inhibition of Nutr1 utilisation by Nutr2:

$\mathrm{U}_{\text {Nutr1 }}=\mathrm{v}_{\max , \text { Nutr1 }} /\left(\left(1+\mathrm{M} / \mathrm{C}_{\text {Nutr1 }}\right) \times\left(1+\mathrm{C}_{\text {Nutr2 }} / \mathrm{J}_{\text {Nutr2 }}\right)\right)$,

where $\mathrm{C}_{\mathrm{Nutr} 2}$ is the intracellular concentration of Nutr2 (mol/l) and $J$ is the inhibition constant (mol/l) for Nutr2 inhibiting the metabolism of Nutr1. A similar equation can be developed for the effect of Nutr1 on Nutr2 metabolism.

Also, effects of hormonal regulation on the enzymic capacity or activity of tissue cells can be represented by (a combination of) the following equations:

$\mathrm{U}_{\text {Nutr1 }}=\mathrm{v}_{\max , \text { Nutr1 }} /\left(1+\mathrm{M} /\left(\mathrm{C}_{\text {Nutr1 }} \times \mathrm{C}_{\text {Hormone }}\right)\right)$

or

$\mathrm{U}_{\text {Nutr1 }}=\left(\mathrm{v}_{\max , \text { Nutr1 }} \times \mathrm{C}_{\text {Hormone }}\right) /\left(1+\mathrm{M} / \mathrm{C}_{\text {Nutr1 }}\right)$,

where $\mathrm{C}_{\text {Hormone }}$ is the concentration of hormone $(\mathrm{mol} / \mathrm{l})$. Often, the presence of a hormone is represented with a relative value that compares hormone concentration with that during a reference physiological state, $\mathrm{C}_{\text {Hormone,ref }}$, by replacing $\mathrm{C}_{\text {Hormone }} / \mathrm{C}_{\text {Hormone,ref }}$ for $\mathrm{C}_{\text {Hormone }}$.

Also, specific functions of the GIW, such as the rate of nutrient and ion transport, or other energy-requiring processes, are mostly enzymically driven and saturate with an increase of rate. Factors influencing the individual physiological functions of the GIW, affecting the enzymically driven processes as well as the mass of GIW tissues involved, may be represented in a similar manner as the effect of hormones, changing the maximum of enzymic activity. Factors influencing the tissue characteristics are, besides tissue mass $\left(\mathrm{Q}_{\text {Tissue }}\right)$, the rate of tissue turnover and the rate of a productive response (of the immune system, synthesis of mucus, synthesis of digestive enzymes), calculated as $\mathrm{Q}_{\text {Tissue }} \times \mathrm{k}_{\text {turnover }}$ and $\mathrm{Q}_{\text {Tissue }} \times \mathrm{k}_{\text {production, }}$, where $\mathrm{k}_{\text {turnover }}$ is the fractional rate of tissue turnover (/d) and $\mathrm{k}_{\text {production }}$ is the rate of the productive response ( $\mathrm{g}$ or mol product/g tissue per $\mathrm{d}$ ).

The requirement of nutrient Nutr for tissue turnover and synthesis of cell products may then be represented by:

$\mathrm{U}_{\text {Nutr }}=\mathrm{Q}_{\text {Tissue }} \times \mathrm{k}_{\text {turnover }} \times \mathrm{R}_{\text {Turnover,Nutr }}$

or

$\mathrm{U}_{\text {Nutr }}=\mathrm{Q}_{\text {Tissue }} \times \mathrm{k}_{\text {production }} \times \mathrm{R}_{\text {Production,Nutr }}$,

where $R_{\text {Turnover,Nutr }}$ and $R_{\text {Production,Nutr }}$ are the specific requirements of the nutrient to maintain tissue turnover and the incorporation of the nutrient into the cell products synthesised.

For a more elaborate discussion of these modelling methods to represent the metabolic activity of various organs or animal metabolism, the reader is referred to the textbooks of Baldwin (1995) and Dijkstra et al. (2005).

\section{Nutrient utilisation by the gastrointestinal wall}

Before giving attention to the individual functions and processes responsible for the metabolic activity and nutrient utilisation by GIW tissues, the more general characteristics of GIW metabolism are discussed first for single-stomached animals and ruminants.

\section{Single-stomached animals}

The GIW metabolism is intensive, with high rates of synthesis and degradation of proteins, carbohydrates and glucoproteins, resulting in high utilisation rates of specific types of amino acids (AA) and glucose. Additionally, there is intensive ion transport across cell membranes. These processes generate a high demand of metabolic energy, which is evident from the significant $\mathrm{O}_{2}$ consumption by all 
portal-drained visceral organs (portal-drained viscera; PDV). In pigs of 3.5-4 months of age Yen et al. (1989) established a PDV share of $37 \%$ of total $\mathrm{O}_{2}$ consumption and after a meal $\mathrm{O}_{2}$ consumption rose by about $50 \%$ compared with the level preceding the meal. McNurlan \& Garlick (1980) concluded that the PDV covers 20-35\% of the total energy utilisation as well as protein synthesis of the whole body, but lower estimates of 10-20\% are suggested by Van Goudoever et al. (2000), which still remains high in comparison with a relative weight of the PDV of about $6 \%$ of total body weight. The PDV organs are responsible for more than $50 \%$ of the total body turnover of some EAA (Stoll et al. 1998; Yu et al. 1992). A comparison of FPSR in various organs of a pig of $44 \mathrm{~kg}$ whole weight indicates that protein turnover rate is many times higher in the PDV than in skeletal muscle (Table 1). A large fraction of the AA supplied from the lumen and by arterial blood is extracted by the GIW. Bertolo et al. (1999, 2000) demonstrated that the SI intervenes more in AA utilisation than the liver. Because of the intensive metabolism and with its apparent dependency on the supply of AA from the lumen, the GIW requires detailed representation in relation to total $\mathrm{AA}$ and energy demand of the whole body (Stoll \& Burrin, 2006).

Nutrients are used to sustain basal functions of cells such as ion transport, cell repair and replacement, costs of basic levels of nutrient transport, mucosa turnover and production of immune cells, immunoglobulins and mucus. Although a large fraction of the secretions will be digested again and absorbed by the GIW (recycling), the synthesis and absorption processes still have a cost of energy, and hence of nutrients. About $10 \%$ of total protein synthesis in the mucosa is related to the net synthesis of mucosal protein and the remainder is secreted to the lumen as digestive enzymes, mucus, immunoglobulins and sloughed mucosal cells (Gaskins, 2003). Therefore, nutritional factors that stimulate the secretory function of the GIT may affect its nutrient utilisation rate.

Various factors have been identified to affect the metabolic activity of the GIW. For example, proliferative effects of volatile fatty acids (VFA), in particular of butyrate, have been established (Sakata, 1987; Lupton \& Kurtz, 1993). A decreased utilisation of leucine by the GIW because of a diminished microflora in the lumen (Nieto \& Lobley, 1999) is an example where digestion and nutrient

Table 1. Protein content, and fractional and absolute rate of protein synthesis in various organs and tissues of a pig of $44 \mathrm{~kg}$ body weight (results derived from Simon, 1989)

\begin{tabular}{lccc}
\hline & Protein & $\begin{array}{c}\text { Fractional } \\
\text { synthesis } \\
\text { Organ or tissue }\end{array}$ & $\begin{array}{c}\text { Synthesis } \\
\text { rate }(\mathrm{g} / \mathrm{d})\end{array}$ \\
\hline Liver & 211 & $19 \cdot 7$ & 41.6 \\
Pancreas & 21 & $81 \cdot 7$ & $17 \cdot 2$ \\
Stomach & 49 & $18 \cdot 1$ & $8 \cdot 9$ \\
Small intestine & 135 & $37 \cdot 5$ & $50 \cdot 6$ \\
Caecum & 8 & $42 \cdot 1$ & 3.4 \\
Colon & 54 & 30.8 & 16.6 \\
Kidneys & 27 & $12 \cdot 8$ & 3.5 \\
Skeletal muscle & 2828 & 3.9 & 110.3 \\
Heart & 23 & $5 \cdot 3$ & 1.2 \\
Skin & 399 & 6.2 & 24.7 \\
\hline
\end{tabular}

utilisation by the GIW are both affected. Stoll et al. (1998) observed that the amount of AA catabolised by the mucosa of piglets (first-pass metabolism) was strongly related to the mass of mucosa present. This means that factors that influence the mucosal mass also strongly determine the utilisation of AA and other nutrients by the GIW. This example is representative of the multiple aspects of GIT functioning that may be affected by nutritional factors; digestive processes (extent and site of digestion, microbial activity), absorptive processes (extent, site and type of transport), secretory processes (digestive enzymes, mucus, immunoglobulins), mucosa metabolic activity (tissue mass, turnover, proliferation, repair, immune response), and type of nutrient supplied to the mucosa (nutrient supply from lumen and by arterial blood). Keeping in mind this complexity, an attempt is made to delineate the effects of specific factors and production conditions on the metabolic activity of the GIW.

Windmueller \& Spaeth (1974, 1975, 1976, 1980) demonstrated that AA, in particular NEAA, play an important metabolic role in the GIW. The crucial observation was made that the GIT removes about $25 \%$ of the glutamine supplied by arterial blood. These observations on glutamine had a large impact on clinical nutrition and led to an extensive investigation of the role of glutamine in GIW metabolism (Smith \& Wilmore, 1990; Hall et al. 1996). Measurements also indicated that glutamine was not only used as a source of energy but that it also served as a precursor for some essential pathways (synthesis of ornithine, citrulline, proline and arginine; Wu, 1998). Besides its role in the functioning of immune cells, glutamine plays a crucial role in the replenishment of metabolic intermediates and the supply of metabolic energy during hypoxic conditions. It is still under debate whether AA utilisation is functional and inevitable, or rather driven by the presence and local supply of AA to enterocytes. It is also not fully clear to what extent the excessive utilisation of AA may be regulated by protein nutrition (Stoll et al. 1998).

Variation in nutrient utilisation by the GIW occurs due to a variable supply and origin of nutrients and competition among nutrients. For example, Fleming et al. (1997) observed an interaction between glucose and glutamine in their contribution to the production of metabolic energy in cells isolated from the rat SI. The percentage of energy produced by glucose metabolism in glycolysis increased from $78 \%$ to $95 \%$ when glutamine was incubated together with glucose. The largest fraction of glucose was utilised for the synthesis of lactate, which corresponds with measurements in vivo. Furthermore, the results also indicate that changes in glucose and glutamine supply have consequences for metabolism of the mucosa cells. With a combination of glucose and glutamine, both nutrients delivered a similar amount of energy (in the proximal part of the SI 62 and $38 \%$, and in the distal part 49 and $51 \%$ ). The intensity of glycolysis was six to seven times higher in cells of the proximal part of the SI compared with those in the distal part. There seems to be a minor contribution of the pentose-phosphate cycle to total glucose utilisation (less than $5 \%$ ). It should be noted that glucose utilisation by isolated GIW in vitro is normally higher than measured in vivo (Reeds et al. 1999). Although in vitro results may not 
be representative from a quantitative point of view, the size of the effects observed by Fleming et al. (1997) indicate that glucose utilisation cannot be neglected in evaluations of nutrient metabolism by the SI or whole GIT. It is necessary to recognise that glucose utilisation by the mucosa depends on the physiological conditions and the nutritional state of the animal, instead of making a general assumption of minor glucose utilisation (Reeds et al. 1999).

There are also several physico-chemical factors that affect feed digestion and nutrient absorption such as viscosity, $\mathrm{pH}$ and osmolarity of digesta. An increase in intraluminal viscosity inhibits the rate of nutrient absorption because of a thickening of the unstirred water layer at the mucosa surface (Johnson \& Gee, 1981). Also the mixing of feed, pancreatic enzymes and bile is inhibited (Edwards et al. 1988), as well as the movement of nutrients to the mucosa surface (Fengler \& Marquardt, 1988) causing a delay in digestive and absorptive processes. A higher viscosity causes a reduction in mixing, a slower passage and less oxygenation of digesta, and may therefore stimulate microbial population (Bedford, 1996). Intraluminal viscosity strongly depends on dietary composition, and measurements in ileum contents in chicks of age $22 \mathrm{~d}$ varied from $2.6 \mathrm{mPa} \times \mathrm{s}$ on a maize diet to $33.5 \mathrm{mPa} \times \mathrm{s}$ on a rye diet (Langhout, 1998). Large differences in viscosity occurred at different sites along the SI. Viscosity in the duodenum and jejunum was several times lower than in the ileum. Another factor to consider is the $\mathrm{pH}$ of digesta, which increases progressively with passage through the stomach and duodenum. Usually, the $\mathrm{pH}$ of ileum contents is efficiently regulated, but dietary measures such as supplementation with organic acids in a matrix, ensuring their gradual liberation, decreased $\mathrm{pH}$ in the ileum in a linear manner (Mroz et al. 2003). This effect is important in relation to the barrier function of the SI and the microbial population hosted in the lumen, and also in relation to the intraluminal production of ammonia and mineral absorption because $\mathrm{pH}$ affects solubility as well as the size of mineral complexes formed (Biagi et al. 2003). A large number of studies have been published concerning the effects of organic acid supplementation or the stimulation of intraluminal production of acids as a means to manipulate the microbial population and $\mathrm{pH}$ of digesta in different compartments of the GIT (for reviews, see Partanen \& Mroz, 1999; Mroz et al. 2005). Intraluminal acids are potentially powerful factors to influence animal performance. Organic acids also have a strong impact on the morphology of the GIW (Pluske et al. 1996) and on the secretion of pancreatic enzymes (Harrada et al. 1986); they serve as a source of energy for metabolism, and there are indications of positive effects on the immune system (Pratt et al. 1996).

\section{Ruminants}

As in single-stomached animals, the FPSR in the PDV is high (Table 2). Huntington \& Reynolds (1987) indicate that $\mathrm{O}_{2}$ consumption by the PDV is about $20 \%$ of that of the whole cow, and appeared evenly distributed over stomachs and intestines.
Table 2. Fractional rate of protein synthesis in various organs of sheep on two levels of feed intake (results derived from Lobley et al. 1994)

\begin{tabular}{|c|c|c|c|c|}
\hline \multirow[b]{3}{*}{ Organ or tissue } & \multicolumn{4}{|c|}{ Fractional synthesis rate $(\% / d)$} \\
\hline & \multicolumn{2}{|c|}{$\begin{array}{c}\text { Feed intake } \\
1.25 \times \\
\text { maintenance }\end{array}$} & \multicolumn{2}{|c|}{$\begin{array}{l}\text { Feed intake } \\
2 \cdot 0 \times \\
\text { maintenance }\end{array}$} \\
\hline & Mean & SD & Mean & SD \\
\hline Liver & $22 \cdot 1$ & 0.7 & 22.5 & 1.2 \\
\hline Rumen & 21.9 & $2 \cdot 1$ & $35 \cdot 3$ & 4.7 \\
\hline Abomasum & 23.5 & $1 \cdot 7$ & $28 \cdot 4$ & $5 \cdot 5$ \\
\hline Duodenal mucosa & 59.5 & 3.3 & 67.5 & $6 \cdot 3$ \\
\hline Duodenal serosa & $41 \cdot 6$ & $4 \cdot 3$ & 44.9 & $3 \cdot 2$ \\
\hline Jejunal mucosa & $64 \cdot 4$ & $9 \cdot 1$ & $66 \cdot 9$ & $2 \cdot 2$ \\
\hline Jejunal serosa & 35.7 & $5 \cdot 7$ & $49 \cdot 3$ & $6 \cdot 3$ \\
\hline Ileal mucosa & $47 \cdot 3$ & 4.4 & $56 \cdot 7$ & $6 \cdot 6$ \\
\hline Ileal serosa & 30.5 & $2 \cdot 0$ & $40 \cdot 7$ & $2 \cdot 8$ \\
\hline Caecum & $20 \cdot 4$ & $1 \cdot 2$ & $34 \cdot 1$ & $7 \cdot 0$ \\
\hline Colon & $26 \cdot 0$ & $2 \cdot \overline{3}$ & $35 \cdot 0$ & 4.0 \\
\hline
\end{tabular}

In non-juvenile ruminants, VFA are the main source of energy for rumen epithelium. Often, variation in relative utilisation of acetate, propionate and butyrate by rumen wall tissues is assumed small (Bergman, 1990). However, a change in VFA supply to the epithelia does not necessarily mean that a similar and proportional change occurs in VFA utilisation. Moreover, various nutritional factors affect the relative proportion of acetate, propionate and butyrate in the rumen (Baldwin, 1995; Bannink et al. 2006b). Depending on the type of VFA involved, VFA are more or less mutually dependent with respect to the enzyme kinetics of their metabolic conversion (Ash \& Baird, 1973; Harmon et al. 1991; Rémond et al. 1995; Bannink et al. 2000; equation 4). This dependency is characterised by competitive inhibition and causes butyrate to strongly inhibit the activity of CoAsynthetases for acetate and propionate (Rémond et al. 1995; Fig. 5), whereas the reverse is not the case. Besides full oxidation, a variable proportion of butyrate is metabolised to $\beta$-OH-butyrate (Bergman, 1990; Britton \& Krehbiel, 1993; Rémond et al. 1995) and part of the propionate may be converted into lactate. Both lactate and propionate are precursors for gluconeogenesis. It remains uncertain, however, to what extent propionate utilisation depends on arterial glucose supply and on the competition among the rumen, other visceral tissues and the udder for arterial glucose. Finally, there are indications that epithelial mass in particular changes with nutrition, instead of the metabolic activity per unit tissue mass. Growth and proliferation of epithelia seems therefore the most important determinant of the energy requirement and of the fraction of the VFA utilised by the GIW (Bannink et al. 2000).

The fraction of VFA metabolised by the PDV in various types of ruminants is presented in Table 3. Although differences in experimental methodology may explain part of the variation observed, a large variation in VFA metabolism seems evident. Moreover, Kristensen et al. $(1998 a, b)$ indicated that VFA appear in portal blood in highly variable amounts and composition (Table 3). Although substantial amounts of VFA (up to a third) flow to the (ab)amosum, enzyme assays indicate that tissues from 

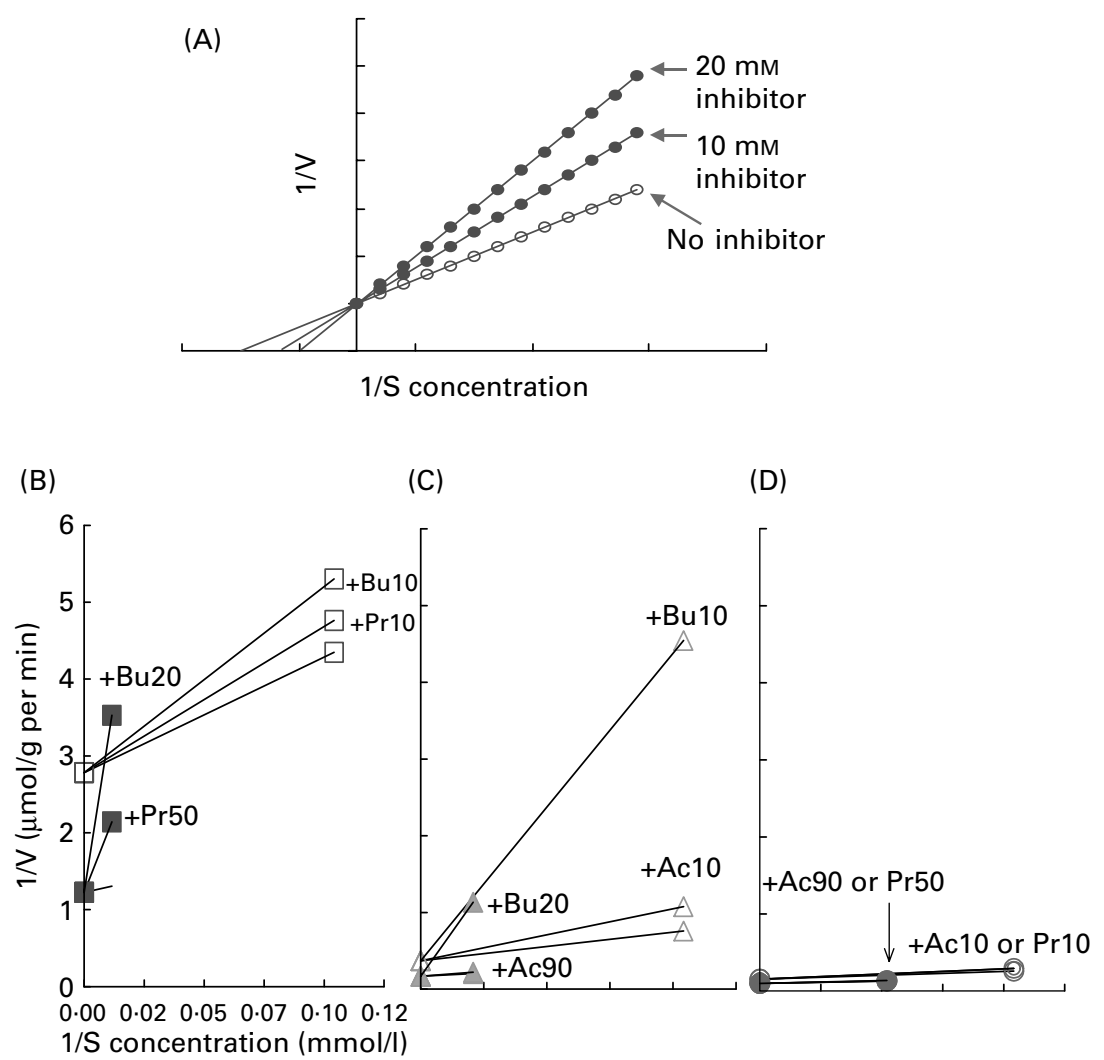

Fig. 5. Comparison of enzyme assays in rumen epithelium by Harmon et al. (1991; $\square, \triangle$, $)$ ) and Ash \& Baird (1973; $\square, \Delta, \bigcirc)$. The effect of inhibiting volatile fatty acid (VFA) on the activity of VFA activation is demonstrated by a double-reciprocal plot of Co-synthetase activity (V; $\mu$ mol/g tissue per min) and VFA concentration of the activated VFA type (S; mmol/l) (A). (B) Acetate ( $\square, \square, A c)$; (C) propionate ( $\triangle, \Delta$, Pr); (D) butyrate $(\bigcirc, \mathrm{O}, \mathrm{Bu})$. Codes and numbers that guide the symbols indicate the type and concentration $(\mathrm{mmol} / \mathrm{l})$ of inhibiting VFA (absence of a guiding code indicates absence of inhibiting VFA). The graphs were derived from Bannink et al. (2000).

these organs have comparable capacities to convert VFA to those established for rumen tissue (Bannink et al. 2000).

As with single-stomached animals, the GIT of ruminants also utilises large amounts of AA supplied by arterial blood. Lindsay \& Reynolds (2005) mention a $35 \mathrm{~g}$ N/d difference between the supply from the lumen and the net amount appearing in the portal blood in beef cattle. This suggests a rather constant AA utilisation by the GIW and a less prominent role of AA such as glutamine as an energy source than in single-stomached animals. However, other studies indicate a much higher AA utilisation by the PDV (discussed later).

\section{Factors affecting gastrointestinal wall physiology}

The GIT supports the digestion of feed and absorption of nutrients. It is also the barrier to the external environment, supports important immune functions and generates endocrine responses to the intraluminal conditions (Burrin et al. 2000). Such essential functions have high metabolic costs. Therefore, quantitative examination of the capacity of nutrient utilisation of the GIW, in relation to the various physiological functions it performs and in relation to the capacity to regulate the nutrient supply to the animal, is required. In this section, the metabolic costs of the physiological functions of the GIW will be discussed, with special emphasis on the SI in single-stomached animals and on the rumen in ruminants.

\section{Gastrointestinal tract mass}

Nutritional factors have a strong impact on the development of the GI and the mass of tissue present. Even more than the metabolic acivity per unit tissue mass, the total mass of mucosa tissues determines the energy and nutrient need by the GIW (equation 8). For this reason, the mass of the GIW is an important factor when evaluating the variability of nutrient utilisation by the GIW. Hence, mass of tissue, in particular that of the epithelia and the cells with a secretory function or involved with the immune reponse, needs to be a direct input to the model of GIW metabolism (Figs. 3, 4 and 7) or to be predicted from nutritional and animal (GIW) characteristics.

Single-stomached animals. The weight of the GIW is strongly related to body weight. Specific feed components such as fermentable carbohydrates resistant to digestion in the SI (Van der Meulen et al. 1997a; Bakker, 1995; Brunsgaard et al. 1995) not only affect the type and location of digestion, but also physiology and growth of the GIW and its proliferation. The high adaptive capacity of the GIW is a general characteristic among animal species.

Brunsgaard et al. (1995) demonstrated in young rats of age $0-6 \mathrm{~d}$ that inclusion of fermentable carbohydrates in the 
Table 3. Measurements of net flux of volatile fatty acids (VFA) in portal blood expressed as a percentage of the quantity formed in the rumen (after Rémond et al. 1995), or as a percentage of metabolisable energy intake (after Kristensen et al. 1998a)

\begin{tabular}{|c|c|c|c|c|c|c|c|c|}
\hline Reference & Animal type & Study & Type of diet & \multicolumn{5}{|c|}{ VFA } \\
\hline \multirow{5}{*}{$\begin{array}{l}\text { Rémond et al. } \\
\text { (1995) }\end{array}$} & & 2 & - & - & 60 & - & & \\
\hline & & 3 & - & 70 & - & - & & \\
\hline & Lambs & 4 & - & 67 & 70 & 22 & & \\
\hline & Steers & 7 & - & - & - & 26 & & \\
\hline & & 8 & $\begin{array}{l}- \\
-\end{array}$ & 82 & 46 & - & & \\
\hline \multirow{9}{*}{$\begin{array}{l}\text { Kristensen et al. } \\
\quad(1998 a)\end{array}$} & Cattle & 1 & $\mathrm{R}$ & & & & 35 & $72: 24: 4$ \\
\hline & & 2 & $\mathrm{R}$ & & & & 40 & $74: 21: 5$ \\
\hline & & 3 & C & & & & 34 & $56: 36: 8$ \\
\hline & & 9 & $\mathrm{R}$ & & & & 16 & $82: 17: 1$ \\
\hline & & 10 & $\mathrm{R}$ & & & & 25 & $90: 9: 1$ \\
\hline & & 11 & C & & & & 33 & $87: 12: 2$ \\
\hline & & 12 & $\mathrm{R}$ & & & & 24 & $77: 22: 1$ \\
\hline & & 13 & $\mathrm{R}$ & & & & 44 & $75: 22: 3$ \\
\hline & & 14 & $\mathrm{C}$ & & & & 43 & $78: 16: 5$ \\
\hline
\end{tabular}

$\mathrm{R}$, roughage-rich diet; $\mathrm{C}$, concentrate-rich diet.

${ }^{*}$ Acetic acid:propionic acid:butyric acid.

diet increased the share of the GIW in whole-body growth (up to $33 \%$ extra whole-body weight, and $45 \%$ extra GIW weight per unit empty body weight). In growing pigs, similar adaptations occur on the inclusion of fermentable carbohydrates in the diet (Bakker, 1995). Substituting cellulose or soya hulls for maize starch during the growth period from 30 to $105 \mathrm{~kg}$ of body weight increased GIW weight up to $6 \mathrm{~kg}$. More recently, Rijnen et al. (2001) obtained comparable results with increasing doses of coconut meal and soyabean hulls on the proportion of GIW in empty-body weight. With increasing dietary content of coconut meal or soyabean hulls from 4 to $48 \%$ of DM the weight of the total GIW, stomach and colon per $\mathrm{kg}$ body weight gradually increased up to a maximum of 24 and $6 \%$, 28 and $15 \%$, and 61 and $29 \%$, respectively. In another study (Rijnen, 2003), substituting raw potato starch for gelatinised maize starch caused a significant shift of the site of starch digestion from the SI to LI and a 9 and $29 \%$ higher weight of total GIW and colon. With straw substitution, the weight of the total GIW and the stomach increased by 7 and $11 \%$, and that of the SI and caecum were hardly affected. Fermentable carbohydrates thus have a strong impact on the GIW development $\left(\mathrm{Q}_{\text {Tissue }}\right.$; tissue turnover rate, equation 7; Figs. 3, 4 and 7) related to digesta mass and organic acid production.

Ruminants. The level of feed intake has a large impact on the GIW mass in ruminants (Smith \& Baldwin, 1974; Van Soest, 1994). Lindsay \& Reynolds (2005) indicate that not only during the growth of juvenile ruminants but also in adult ruminants the GIW and liver keep their plasticity to a large extent and up to a doubling of rumen, SI and liver weight is possible during pregnancy and lactation. Baldwin (1995) mentions $34 \mathrm{~kg}$ of weight of the GIW of a lactating cow, which is $28 \%$ more than during the dry period. Similar changes have been established in other animal species such as rats, which indicates that the impact of stage of lactation and level of feed intake on the GIW mass is comparable across animal species (Baldwin, 1995). Considering the high metabolic activity of the GIW and the morphological traits of dairy cattle selected for high yields, the impact of the GIW on energy metabolism and nutrient supply to the cow probably becomes increasingly important when productivity rises as indicated by the increased maintenance requirements, measured by indirect calorimetry, of moderntype high-yielding dairy cattle compared with low-yielding dairy cattle (Kebreab et al. 2003).

Besides feed intake the dietary composition affects the GIW mass $\left(Q_{\text {Tissue }}\right.$; tissue turnover rate, equation 7; Figs. 3, 4 and 7). With reference to rumen mass, the dietary concentrate proportion is an important stimulatory factor for rumen epithelia mass and size of rumen papillae (Dirksen et al. 1984), and the absorption capacity of the rumen wall. This stimulatory effect is probably related to the increased production of VFA. Proliferation of rumen epithelia may also be stimulated in a more indirect manner. Regulation by hormones secreted locally, or by increased concentrations of hormones in the circulation as a response to an increased consumption of starch by the dairy cow in early lactation, may cause proliferation of epithelial tissues and a higher 
epithelial mass (Sakata et al. 1980; equations 5 and 6). Although during early lactation peripheral tissues and the GIW might be relatively insensitive to the influence of insulin, other hormones (for example, insulin-like growth factor 1; Shen et al. 2004) still may have an effect.

\section{Tissue turnover and proliferation}

Several nutritional factors affect the turnover and proliferation of the mucosa by changes in the rate of cell division in the proliferative zone of the epithelia (crypts). These factors may vary from nutritional (lumen conditions), to physiological (hormones, arterial nutrient supply, physiological state) and immunity factors (pathogens, mucosal damage, increased wearing or degradation of mucus and mucosa). Particularly nutrients in the lumen are strong stimuli to synthesis rates of crypt cells, but also hormones, inflammatory mediators or other specific factors may have an effect. The process of tissue turnover has a high metabolic cost, strongly determines nutrient requirement by the GIW and may become an estimated maximum of $50 \%$ of the total requirement of the GIW (for example, infection, high levels of feed intake, with antimicrobials) and a somewhat smaller, but still very high, percentage of the whole-body protein turnover. Therefore, tissue turnover is an essential input to the model of nutrient metabolism by the GIW, either a direct model input or predicted from indirect nutritional and animal factors (equation 7; Figs. 3, 4 and 7).

Proliferation is one mechanism to ensure optimal functioning of the mucosa despite highly variable nutritional conditions. Proliferation will have large consequences for the nutrient utilisation by the GIT and the energy costs of tissue turnover. In addition, other energy-requiring processes will change, including the transport rates of ions and nutrients. As a result, energetic consequences of proliferation will be much larger than solely the costs involved with turnover of the tissue. Baldwin (1995) argued that $40 \%$ of total heat production by the GIT is attributed to tissue turnover, whereas $60 \%$ is caused by other synthetic and maintenance processes, of which half is attributed again to transport of ions and nutrients.

In ruminants, VFA strongly determine the metabolism of rumen epithelia that need to adapt to exposure to high VFA loads. In vitro studies identified butyrate as a key factor in rumen epithelial proliferation (Galfi et al. 1991), which is confirmed in vivo (Reynolds \& Huntington, 1988a,b). In comparison with a roughage diet, a concentrate diet offered to beef steers showed a three-fold higher net appearance of butyrate in portal blood in combination with a ten-fold and six-fold increase of the net utilisation of AA and glucose (and halving of the net appearance of lactate) by the stomachs. This indicates a higher rate of metabolism and protein synthesis by stomach tissues. The total net appearance of VFA units (acetate + propionate $+2 \times$ butyrate $+2 \times \beta-\mathrm{OH}$-butyrate) was slightly lower on the concentrate diet despite its higher digestibility, indicating a higher rate of VFA utilisation by the stomach tissues. Similarly, Krehbiel et al. (1992) established a $28 \%$ lower net portal appearance of AA with intraruminal infusions of butyrate. Finally, Nozière et al. (2000) observed a strong proliferative action of intraruminal infusion of butyrate in underfed ewes with much lower (negative) rates of net portal appearance of EAA compared with infusions of mainly acetate and propionate.

Butyrate is not only associated with proliferation as an adaptive response of the epithelium, but also with the occurrence of para- or hyperkeratosis and structural changes during which proliferation is actually inhibited and cell differentiation stimulated (Gäbel et al. 2002). Thus, diets high in energy, offered for long periods, may have contrasting effects on the morphology and functioning of rumen epithelia and the corresponding nutrient utilisation. Insight into mechanisms of responses for the in vivo situation in ruminants still seems inadequate (Gäbel et al. 2002).

\section{Transport of nutrients and ions}

Permeability of mucosa is defined as the capacity of specific compounds to penetrate the GIT by diffusion without interference of active or facilitated transport mechanisms (Montalto et al. 1997). This permeability is a useful concept to study the integrity and functionality of the mucosa (Jeurissen et al. 2002). The concept might also be useful to study the transport route of ions and nutrients in relation to the mucosal metabolism and integrity, but this application seems lacking in the literature. The nutrient cost involved depends on the mechanisms of the different routes of transport (transcellular $v$. paracellular, passive diffusion $v$. facilitated or active transport) and the maintenance functions required to keep the intracellular milieu within narrow physiological and biochemical limits. These costs can be substantial, as will be discussed later, with an estimated maximum of $50 \%$ of the total energy requirement by the GIW (for example, with high levels of feed intake) and of the whole body as well. For this reason, the explicit representation of the metabolic costs of nutrient and ion transport is an essential element of every model of GIW metabolism (Figs. 3, 4 and 7). Part of these costs may be directly related to nutrient transport; however, the main part is involved with maintaining tissue functionality and therefore needs to be an independent input to the model or needs to be predicted from nutritional or animal (GIW tissue) characteristics.

The mucosa contains $\mathrm{Na}^{+}$-dependent carrier systems for the transport of AA and glucose. Different AA, and AA and glucose, have some of these carrier systems in common, causing competitive inhibition of their transport rate (Vinardell, 1990), absorption kinetics, intracellular concentrations and utilisation rate by the mucosa. Transport of monomers such as glucose and AA is mainly $\mathrm{Na}^{+}$ dependent and requires ATP. In various models, a requirement of $0.33 \mathrm{~mol} \mathrm{ATP} / \mathrm{mol}$ monomer transported is assumed (Gill et al. 1989; Gerrits et al. 1997), although the precise costs vary with the processes taken into account by these figures. Transport of short-chain peptides is $\mathrm{Na}^{+}$ independent, independent from that of glucose and AA, but still a function of peptide concentration according to enzyme kinetics in the absence of any ion gradient across the mucosal membrane. Nutrients may also be transported by passive diffusion that does not directly require energy 
and follows a concentration gradient (perhaps indirectly to maintain intracellular homeostasis). Particularly VFA may be transported by active or facilitated transport as well as passive diffusion, which both saturate with increasing VFA concentration because ATP-requiring enzyme kinetics are involved, and (probably) concentration gradients become smaller (Lopez et al. 2003). With pH values below 6·0, VFA mainly diffuse passively, whereas with rumen $\mathrm{pH}$ above $6 \cdot 0$ most VFA are present in the non-diffusible anionic form and are transported by active or facilitated transport (Dijkstra et al. 1993; Gäbel et al. 2002).

Energetic costs of transport of several types of nutrients and ions are summarised in Table 4. Ion transport takes a substantial part of the total energy utilisation in tissues and the whole body as demonstrated by estimates of Summers et al. (1988) for a fasting animal. These estimates show that ion and $\mathrm{Na}^{+}$-dependent nutrient transport together are about a quarter of whole-body energy utilisation, and more than a third of that by the GIT. Hormones may affect the costs of nutrient and ion transport. Summers et al. (1988) indicated that the $\mathrm{Na}^{+}, \mathrm{K}^{+}$ATPase activity in muscle tissue of sheep increased by $46 \%$ because of increased levels of thyroid hormone. Thus, hormonal effects are not necessarily limited to nutrient transport and the synthesis and degradation of proteins, but may also affect the basal maintenance processes in cells. Maintenance and synthetic processes are hard to distinguish from each other and increased FPSR is accompanied by increased ATP use for $\mathrm{Na}-\mathrm{K}$ transport (Summers et al. 1988). Although estimates may differ among different sources in the literature, it appears that with an increase of the metabolic activity or protein turnover in cells, the absolute rate of ion and nutrient transport and the energy costs to sustain this will also increase with a similar order of magnitude. This also explains the strong effect of the level of feed intake on the energy costs for ion and nutrient transport in the GIW. Baldwin (1995) evaluated the influence of the stage of lactation on the contribution of the GIT to total maintenance heat production by dairy cows, and this contribution increased from $7.2 \%$ during the dry period to $8.4 \%$ during lactation with GIT weight from $4 \cdot 1$ to $5 \cdot 2 \%$ of total body weight. Milligan \& McBride (1985) observed in sheep that were fasted, fed at maintenance,

Table 4. Estimated energy costs associated with the active or facilitated transport of ions and nutrients (based on Gill et al. 1989; Baldwin, 1995; Gerrits et al. 1997)

ATP utilised

Type of ion or nutrient (mol ATP/mol units transported)

\begin{tabular}{lc}
\hline $\mathrm{K}^{+}$ & $0^{*}$ \\
$\mathrm{Na}^{+}$ & 0.25 or $0.5 \dagger$ \\
$\mathrm{Ca}^{2+}$ & 0.5 to 1.0 \\
$\mathrm{Mg}^{2+}$ & 0.33 \\
$\mathrm{PO}_{4}{ }^{3-}$ & 0.5 to 1.0 \\
$\mathrm{H}^{+}$and $\mathrm{HCO}_{3}^{-}$ & 0.05 to 0.1 \\
Pyruvate and lactate & 0.25 to 0.33 \\
Volatile fatty acids & 0.33 \\
Amino acids & 0.33 to $1.0 \ddagger$ \\
Glucose & 0.33 \\
\hline
\end{tabular}

*Anti-transport with $\mathrm{Na}^{+}$

† Two types of pumps with different efficiency.

$\ddagger$ Distinction between uptake from blood or from lumen, in- or exclusive reabsorption and transport of endogenous protein, in- or exclusive $\mathrm{Na}^{+}$-independent transport. or fed above maintenance, that total and Na,K-ATPasedependent $\mathrm{O}_{2}$ consumption by mucosa increased by 17 and $150 \%$ with feed intake. Therefore, with increasing levels of feed intake the relative contribution of the energy requirements for ion transport in total energy requirements becomes larger. Gill et al. (1989) performed a modelling exercise to evaluate the contribution of ion transport and protein turnover of the various organs in lambs to that of the whole body. They concluded that the GIT was among the organs with the highest contribution of 39 to $50 \%$ and 21 to $26 \%$ of the $\mathrm{Na}-\mathrm{K}$ transport and protein turnover of the whole body. Further, with an increase in feed intake, the whole-body ATP utilisation, protein turnover and $\mathrm{Na}-\mathrm{K}$ transport of the GIT increased by 30,32 and $64 \%$. From the experimental and modelling results it is concluded that the energy requirements for ion transport increase relatively faster than those for protein turnover as a response to increased feed intake. Therefore, emphasis on explicit representation of the metabolic costs of ion transport is required in evaluations of nutrient requirement by the GIT (equation 3; Figs. 3, 4 and 7).

Volatile fatty acids. As described previously, during transport of VFA through the reticulo-rumen wall, substantial VFA metabolism takes place. Compared with intestinal tissues the utilisation of glucose (mainly supplied by arterial blood) seems to play a minor role in rumen tissues (Rémond et al. 1995). From theoretical considerations, a dependency has been suggested between VFA transport, intracellular VFA concentrations and VFA metabolism by rumen epithelia (Bannink et al. 2006a; Gäbel et al. 2002; Fig. 6). The implications would be that the metabolism of proliferated rumen epithelium would affect the kinetics of VFA absorption and VFA metabolism, whereas these aspects are normally treated as independent variables with considerations of VFA utilisation (Britton \& Krehbiel, 1993). Principles proposed for rumen epithelia (Gäbel et al. 2002; Fig. 6) largely correspond to those for the LI epithelia (Rechkemmer et al. 1995).

Considerable energy costs are involved in VFA transport. McBride \& Kelly (1990) found that in response to a single daily meal the $\mathrm{O}_{2}$ utilisation by the rumen epithelium for $\mathrm{Na}^{+}, \mathrm{K}^{+}$-ATPase as well as for other functions increased during the first few hours after the meal by 20 to $30 \%$. Although the contribution of $\mathrm{Na}^{+}, \mathrm{K}^{+}$-ATPase remained rather constant at $25 \%$, irrespective of the type of diet or the moment of measurement, the absolute energy costs involved vary with the course of rumen fermentation and with VFA supply rate to the epithelium. Besides the direct energy costs of VFA transport (presumed to be $0.33 \mathrm{~mol} \mathrm{ATP} / \mathrm{mol} \mathrm{VFA}$ transported; Table 4), there are additional energy costs for regulation of the intracellular $\mathrm{pH}$ and the prevention of intracellular acidosis (Gäbel et al. 2002) that may require more energy than the direct energy costs of VFA transport. In a comparable manner, Gill et al. (1989) calculated that the energy costs of AA transport are relatively small compared with the energy costs of $\mathrm{Na}^{+}, \mathrm{K}^{+}$-ATPase. The results of McBride \& Kelly (1990) suggest that the maintenance of $\mathrm{Na}^{+}-\mathrm{K}^{+}$homeostasis and integrity of rumen epithelia rather than nutrient transport is the most determinant factor of variation in $\mathrm{Na}^{+}, \mathrm{K}^{+}$-ATPase activity. Experimental evidence indeed indicates that the rumen epithelium adapts by ion 


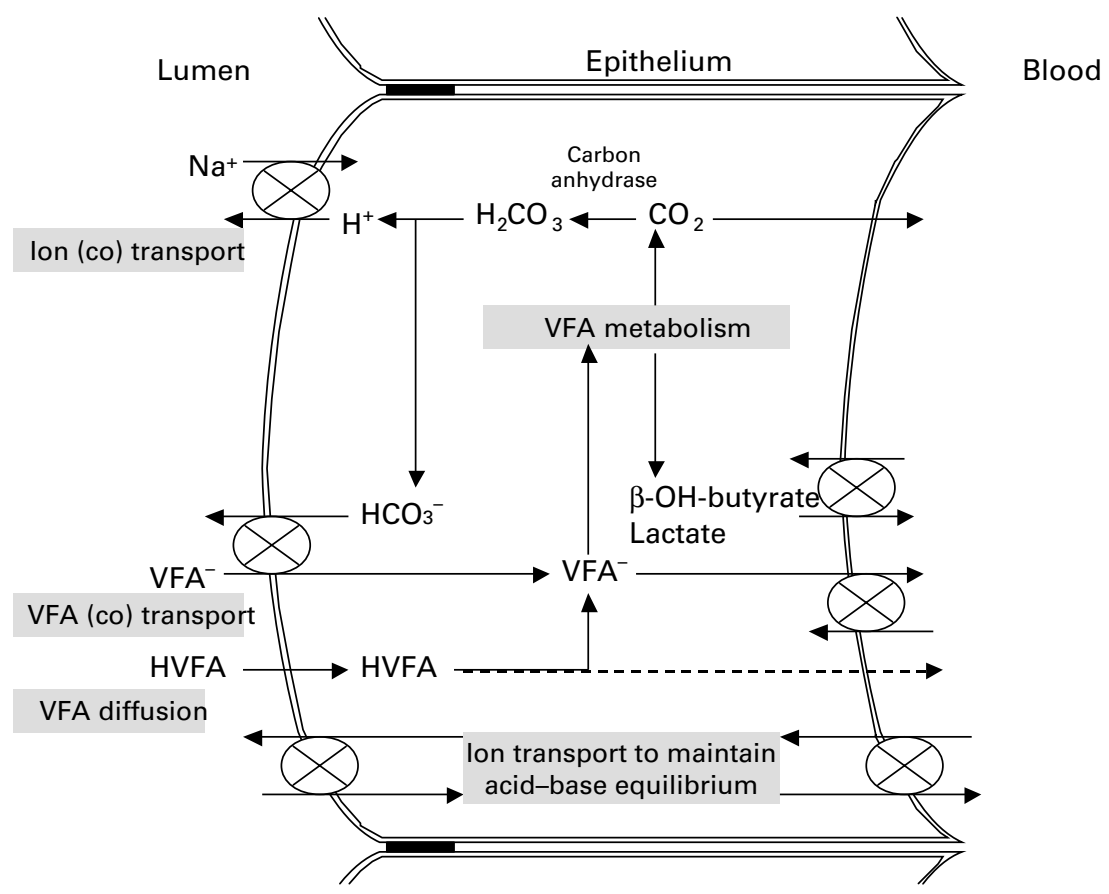

Fig. 6. Schematic representation of the transport of volatile fatty acids (VFA) and ions in rumen epithelium (Bannink et al. 2006a; adapted from Gäbel et al. 2002).

transport and exchange of $\mathrm{Na}^{+}$and $\mathrm{H}^{+}$as well as VFA anions and bicarbonate. Carbon anhydrase activity leads to the synthesis of bicarbonate from $\mathrm{CO}_{2}$ (Fig. 6). This route of $\mathrm{CO}_{2}$ disposal was argued to be more important than disposal to blood, and of more importance for buffering rumen contents than saliva production (Gäbel et al. 2002), but no clear evidence is present.

\section{Resident microflora}

The presence of a microflora strongly directs the metabolic activity of the GIW, and may become very prominent in certain conditions such as with intraluminal colonisation by pathogens. According to the current modelling approach its effects are not explicitly represented as a direct input to the model, but affects multiple factors such as the immune response, mucus synthesis and tissue turnover rate (Figs. 3, 4 and 7). Consequently, the metabolic costs involved with the GIW response to the resident microflora or a change of this microflora (for example, infection) must be expected to be substantial.

Single-stomached animals. The recent ban on the use of antibiotics as growth promoters caused a renewed interest in immunological effects and the growth-regulating functions of the GIT. Micro-organisms in the lumen have a protective as well as a nutritional role for the host (Gaskins, 2003). Simultaneously, the host invests heavily in keeping microorganisms outside the mucosa and reacts with acute immune responses if micro-organisms break through the mucosal defensive mechanisms.

The presence of a microbial population means that it competes with the host for nutrients in the GIT. Additionally, micro-organisms in the lumen have a stimulatory effect on cell turnover in the mucosa and on rates of secretion. The stomach and the proximal duodenum contain relatively few micro-organisms because of the low $\mathrm{pH}$ values and high passage rates of digesta. In the SI, the fractional passage rate of digesta often exceeds the fractional growth rate of most types of micro-organisms. Hence most micro-organisms found in the SI colonise the mucus layer on the mucosa or on the mucosa surface (Gaskins, 2003). In the stomach and proximal duodenum acid-resistant lactobacilli survive and lactate concentrations are found in the stomach digesta (Mroz et al. 2005). The ileum as the most distal part of the SI contains a large and more heterogeneous microbial population. In the LI of the pig an extensive colonisation occurs, depending on the type of substrate flowing into the LI, which may cause extensive fermentation (Bakker, 1995; Van der Meulen et al. 1997a).

In relation to the impact of GIT health on growth performance of single-stomached animals, particularly the SI seems to be important. The presence of a well-developed endemic microbial population may limit the development of non-endemic populations, including pathogens. Endemic micro-organisms have an inhibiting effect on the colonisation of new species by competition for suitable attachment sites and nutrients, and by secretion of anti-microbial factors or by changing actively the local growth conditions. Stimulating such an endemic microbial population partially counterbalances the potential production losses resulting from the ban on antibiotics.

The endemic micro-organisms also have a beneficial effect on the development of the immune system in the GIT. The non-pathogenic endemic micro-organisms act as antigens to stimulate the development of several defence mechanisms. The development of these systems is accompanied with high costs of energy for the host. 
The manner in which these defence systems are activated, and how inflammation mediators are involved in this, is highly complex and is not a subject of the present review. It is important to note, however, that the defence is not restricted to activation of the mucosal immune system but may activate a series of physiological functions such as blood flow, motility of the GIT and the secretion of water and ions (Chang \& Rao, 1994), causing an increased rate of digesta passage (Nabuurs, 1991). The intensity of damage and the subsequent immune response and secretions by the mucosa determine the duration and the extent of nutrient costs for full recovery of the mucosa.

Furthermore the endemic microbial population delivers nutrients to the host from substrates that are difficult to degrade otherwise. First, mucus and digestive enzymes become available again for absorption by the host after microbial degradation, and without micro-organisms these compounds might accumulate (Gaskins, 2003) and be lost for the host. Second, the micro-organisms in the GIT have an important role in fermentation of structural carbohydrates (fibrous compounds) to produce VFA for host metabolism. An intensive fermentation in the lumen stimulates the development of the GIT and its nutrient utilisation. Besides VFA, other valuable compounds also become available for the host such as vitamins and AA.

Micro-organisms may also produce metabolites with a negative effect on the functioning of the GIW (Gaskins, 2003), including amines, ammonia, phenols and indols as endproducts of partial AA fermentation. In addition, fat digestion may be inhibited because of the microbial degradation of bile salts. The mucus layer may be undermined by extensive microbial colonisation that causes mucus degradation and extra energy costs because of the necessity of an increased rate of mucus synthesis. Such effects of the microbial population have a direct influence on digestive processes and the nutrient costs involved in functioning of the GIT. Gaskins (2003) concluded that many of the positive and negative effects of the microbial population in the GIT mentioned here have been insufficiently investigated in single-stomached animals. There is relatively little information on the variation that occurs in the relationships between host and intraluminal microbial population, on the influence of nutrition on microbial ecology in the GIT and the nutrient costs associated with this, and on the nutrient costs associated with infection and damage of the mucosa.

Ruminants. There is not much information on adaptation of the rumen wall to the presence of micro-organisms, apart from an effect of VFA as discussed earlier. Parker (1990) described that the effect of nutritional factors and of the intestinal microbial population on mucosa functioning may be ascribed to a reduced rate of cell division in the crypts and of cell migration to the villus tip. Results from Parker (1990), who added avoparcine to a pelleted diet for weaned lambs during 6 weeks, indicated a severe decrease of the rate of cell division in the crypts of the SI. Such effects, however, are not to be expected in mature ruminants.

\section{Mucus secretion}

Compared with the metabolic costs involved with nutrient and ion transport and tissue turnover, fewer costs are involved with the synthesis of mucus (the same holds for digestive enzymes). Nevertheless, the costs are still significant (estimated to be up to a maximum of tens of percentage of the total energy costs of GIW metabolism) and therefore mucus synthesis requires a separate representation in a model of GIW metabolism (equation 8; Figs. 3, 4 and 7).

The GIT is permanently covered by a strongly adherent layer of glycoproteins of high molecular weight and secreted by specialised goblet cells in the mucosa (Fig. 2). The mucus is a complex biofilm containing proteins, fats and bacteria in a gel-like matrix (Lamont, 1992). The most important proteins are mucins, a family of closely related glycoproteins. The characteristics of the mucus layer are that of a semi-solid gel which creates an important barrier for micro-organisms in the lumen of the GIT and the toxins produced by them, but also a diffusion barrier for dissolved compounds of low molecular weight (Lamont, 1992). Glycoproteins in mucus have highly comparable characteristics among various mammalian species (Lamont, 1992).

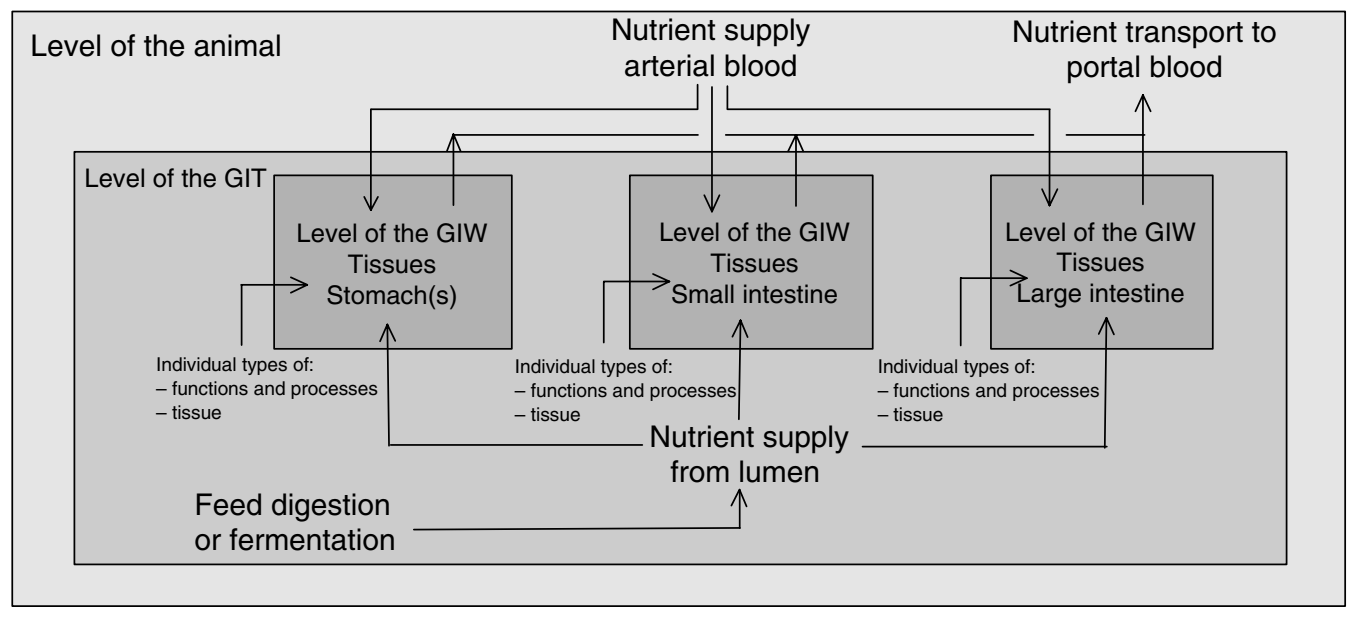

Fig. 7. Schematic representation of the modelling approach including the anatomical compartmentalisation of the gastrointestinal tract (GIT) and of the tissues of the gastrointestinal wall (GIW). For details on the distinction between model inputs, model representation and model outputs, see Fig. 3. 
The basic structure of mucins is a peptide chain with oligosaccharides attached to it in a radial orientation; the peptide chain represents about 15 to $20 \%$ of the molecular weight. The glycosilated part is rich in serine, threonine and proline, whereas the non-glycosilated part is rich in cysteine, serine, glycine, alanine, leucine, glutamate and aspartate and is folded in a comparable manner to many immunoglobulins (Mantle \& Allen, 1989; Forstner \& Forstner, 1994). The oligosaccharides are strongly hydrophilic, promote water binding and support the formation of the gel-like characteristics, prevent degradation of the peptide chain by proteases from the pancreas and bacteria, and bind pathogens, parasites and toxins. The hydrophobic areas may be involved with the binding of fats and with interactions in protein-protein interactions. Reeds et al. (1999) indicate that the most important mucins produced by the mucosa are rich in cysteine, threonine, proline and serine, and concluded that substantial changes in mucus secretion have a measurable effect on the cysteine and threonine requirements of an animal.

Mucins contain binding sites that are in competition with receptors in enterocytes for binding proteins on the surface of micro-organisms. Besides these mucin-binding sites, enterocytes also secrete proteins that coat the microbial binding proteins. Mucins are continuously undergoing digestion and wearing at the luminal side, which is compensated by continuous secretions by goblet cells at the mucosal side of the mucus layer. Moreover, the mucus is continuously transported through the GIT including the cellular fats, DNA, proteins, sloughed epithelial cells and micro-organisms captured by it. By these mechanisms, the mucus protects the mucosa from invasion by micro-organisms. The viscosity of mucus depends on the type of stimulus as well as intraluminal $\mathrm{pH}$ (increased viscosity with lower $\mathrm{pH}$ ). A higher rate of mucus secretion may be a response to many physiological and pathological stimuli, such as bacteria, bacterial toxins, inflammation mediators, chemical stimuli or neural stimuli. The density of goblet cells increases from the proximal duodenum to the distal rectum. Locally, there may be a large variety of goblet cells and types of mucins produced.

A general characteristic of mucins is their potential to bind lipids and NEFA by hydrophobic interactions with the peptide chain or by covalent bonds, respectively. Mucins from the stomach of the pig contain a considerable amount of NEFA, phospholipids, sphingomyeline and cholesterol. A layer of phospholipids directly bound to the mucus layer covers the stomach epithelium (Lamont, 1992). Presence of the phospholipid layer increases the resistance of the mucosal membrane of epithelial cells, which appears important for the prevention of mucus degradation and intracellular acidosis. Mucosa of the stomach as well as the intestines responds by the secretion of bicarbonate upon prolonged presence of acid in the lumen (Allen et al. 1993). This secretion is the result of a stimulated secretion of bicarbonate by mucosal metabolism and an increased permeability of the mucus layer for bicarbonate diffusion. This capacity of the mucosa plays an important role with the repair of the mucus layer after damage or detrimental influences. Chronic or acute infections of the GIT are associated with a reduced basal secretion rate of bicarbonate by the mucosa (Flemström \& Isenberg, 2001). Damage of the stomach mucosa alone seems insufficient to provoke an infection, but it may be in combination with additional factors such as metabolic acidosis or reduced bicarbonate secretion (Allen et al. 1993). Finally, regulation of the intracellular $\mathrm{pH}$ of epithelial cells is closely associated with intensive ion transport. Particularly the $\mathrm{Na}^{+}-\mathrm{H}^{+}$anti-transporter seems involved, but only in the case of a high acid load in the lumen or when bicarbonate secretion is insufficient to guarantee neutral intracellular $\mathrm{pH}$ values (Allen et al. 1993).

\section{Immune cells and immune response}

The immune system is an integral part of the GIT (Goddeeris et al. 2002) and the majority of the immune cells in the whole body are located in the GIT. Energy costs involved in the immune response of the GIT may therefore be quantitatively far more important than that of the remainder of the body. Physically, the immune system is indistinguishable from mucosa and contributes significantly to the nutrient requirement of the GIW. The contribution of the immune response to the total energy requirements of the GIW seems more variable (from less than 10 to about $50 \%$ ) than that of the other individual functions and processes considered (Figs. 3, 4 and 7; immune response may involve cell turnover as well product synthesis; equations 7 and 8). The maximal contribution must be expected during infections and probably may become larger than that of tissue turnover and nutrient and ion transport.

Dugan et al. (1994) indicated that intra-epithelial lymphocytes (first-line defence against antigens from the diet or against pathogens) represent $15 \%$ of the total number of cells in the GIT epithelium. A comparison with the estimation of the total number of leucocytes of $4 \mathrm{~g} / \mathrm{kg}$ total body weight (Klasing \& Calvert, 1999) indicates that the GIT is strongly equipped with immune cells. An activation of the GIT immune system is thus expected to have a large impact on the nutrient utilisation by the GIT. For example, theoretical considerations with regard to a maximum immune response in poultry led Klasing \& Calvert (1999) to conclude that about $60 \%$ of the reduced growth performance may be explained by an increased utilisation of lysine by several components of the immune system. Other AA are involved in the synthesis of nucleic acids and peptides such as glutathione that stimulates gluconeogenesis in the liver (Klasing \& Calvert, 1999). Finally, the availability of preformed monomers of macromolecules such as DNA, RNA and fats may also affect nutrient utilisation by enterocytes and immune cells (Bueno et al. 1994; Waheed et al. 1998; Webb \& Bergman, 1991) during immune activation.

Large changes occur in the metabolism of intra-epithelial lymphocytes as a result of weaning and these changes may be related to a change of diet and the consequences for digesta, antigens and microbial population present in the lumen. Dugan et al. (1994) isolated intra-epithelial lymphocytes from the mucosa of the jejunum and determined the utilisation rate of glucose and glutamine on 21 (moment of weaning), 29 and $56 \mathrm{~d}$ of age. Extra glucose utilisation but rather unchanged glutamine utilisation was observed as a response to weaning which suggests a sparing effect on glutamine utilisation that may serve two purposes: (1) saving 
glutamine for the synthesis of immunologically important molecules (arginine, RNA, DNA), or (2) saving glutamine as a source of energy and as a precursor for the synthesis of citrulline. The latter seems functional because for citrulline (precursor for arginine) as well as for proline, substantial increases in production level occur after weaning (Wu et al. 1994). Consequently, proline and arginine may be EAA for young piglets around weaning, while this is not the case at a later stage of growth. Experimental results also suggest that the profile of AA required for the immune system differs substantially from that for growth (Reeds et al. 1994; Klasing \& Calvert, 1999).

Besides the synthesis of immune cells, also IgA synthesis is an essential element of the GIT immune response (equation 8). The production of $\operatorname{IgA}$, as the most important immunoglobulins secreted by the GIT, is a highly specific and central element of the immune response (Alverdy, 1990) performed by specialised cells in Peyer's patches in the mucosa (Fig. 2). These $\operatorname{IgA}$ are resistant to enzymic breakdown, changes in temperature and $\mathrm{pH}$, and thereby prevent colonisation of micro-organisms in the mucosa. Lymphocytes are released by the GIT to the blood circulation and thereby may not only reach the mucosa but may penetrate other mucosa in the body as well. The GITassociated lymphatic system therefore plays an important regulatory role in supplying antigen-specific IgA to all kinds of mucosa. The importance of IgA for proper functioning of the GIT is underlined by the observation that $\operatorname{IgA}$ deficiencies are associated with a reduced barrier function of the GIT and the occurrence of infections. Contents of lysine in acute-phase proteins and IgA are comparable with that of body protein accretion, whereas contents of phenylalanine, tryptophan and threonine are higher. An increased supply of glutamine may stimulate the immune system and the presence of $\operatorname{IgA}$ in mucosal tissue, which in turn inhibits the translocation of bacteria via the GIW. Other AA (arginine, asparagine, aspartate, glycine, histidine, proline, serine) have a much lower stimulatory effect (10$20 \%$ of that by glutamine; Alverdy, 1990), indicating the specific role of glutamine. Burrin \& Reeds (1997) indicate, however, that it is still uncertain whether glutamine serves as a source of energy or whether it fulfils more specific functions such as the stimulation and regulation of functioning of the immune system.

\section{Gastrointestinal tract development in juveniles}

Growth of juvenile animals is accompanied by a rapid development of the digestive organs (organ mass, organ length, volumes secreted). Large changes occur in the GIT and GIW to install the specialised functions of the GIT during the fetal and the postnatal period with maternal feeding and weaning (Sangild, 2001) with very intensive cryptogenesis and proliferation. Substantial changes occur in gene expression of enzymes, transport proteins and receptors for circulating and luminal trophic factors (Perozzi et al. 1993) with a large spatial diversity in gene expression between the highest and lowest villus position, and between the proximal and distal sites in the GIW.

Functioning of the GIW is related to the secretion of hydrolytic enzymes in the membrane of the brush border and in the cytosol of enterocytes in the SI (equation 8). Feeding colostrum to newborn piglets causes a rapid increase in the content of these enzymes (Sangild et al. 1996) irrespective of the conditions of birth. The protein content of the mucosa $\left(v_{\text {max,Nutr }} \times Q_{\text {Tissue }}\right.$ in equation 3$)$ doubled from about 100 to $200 \mathrm{mg}$ protein/g mucosa at age $2 \mathrm{~d}$, and the content of some brush-border enzymes strongly increased, indicative of the large changes in functioning of the GIW. Colostrum and milk contain a variety of hormones and peptides with a known stimulatory effect on cell growth and differentiation (Houle et al. 1997).

In older and weaned piglets, enzymic and morphological changes in the GIW continue and depend on the diet (ad libitum feeding $v$. restricted feeding, Kelly et al. 1991; dry starter feed v. milk, Pluske et al. 1996). Generally, villus height is decreased and crypt depth increased with feeding dry starter feed and restricted feeding in comparison with non-weaning, milk feeding and ad libitum feeding (Pluske et al. 1996; Van Beers-Schreurs, 1996; Verdonk, 2006). Effects occur at all locations in the SI and demonstrate that the type of feed may have a large impact on the functional characteristics of the GIT and probably also on the functioning and nutrient utilisation by the GIW. Additionally, specific dietary compounds may affect the functioning of the GIW. Van Leeuwen \& Versantvoort (1999) reported that an increased dietary tannin content from faba beans caused a halving of the aminopeptidase activity in the proximal jejunum, a shift of this activity to the distal jejunum and a reduced faecal protein digestibility from 83 to $75 \%$.

The mechanisms underlying the diet-induced changes in the development of the GIW in juveniles are highly complex (Buddington, 1998; Jensen, 1998) because of interactions between digestion, nutrient supply, GIW development and the resident microflora (Maxwell \& Stewart, 1995). Several studies have been performed to study the effect of supplementing single nutrients in piglet diets. Ewtushik \& Ball (1998) showed stimulating effects of arginine and glutamine on duodenal weight, duodenal mucosa weight, mucosa width, villus height and crypt depth. Nucleotides may serve as preformed monomers for DNA and RNA synthesis by a nutrient-sparing metabolic route in tissues with an intensive nucleotide synthesis rate, and hence benefit animals during the period of weaning. Results of Bueno et al. (1994) demonstrated that nucleotide supplementation in rats that recovered from diarrhoea increased the villus height: crypt depth ratio, whereas the number of goblet cells and intra-epithelial lymphocytes were increased and reduced respectively in the duodenum, jejunum and ileum. These results suggest that nucleotides stimulated the recovery of the GIT from diarrhoea although recovery appeared still incomplete after $14 \mathrm{~d}$. Furthermore, polyamines may be a direct source of energy for the GIT during growth or fasting. In contract to Bueno et al. (1994), Bardocz et al. (2001) showed that increased uptake of polyamines was accompanied by an increase in GIT weight and length $\left(\mathrm{Q}_{\text {Tissue }}\right)$, and in protein, RNA and DNA content of SI mucosa (representative of synthetic capacity and tissue turnover rate; equations 7 and 8).

The physiological state of the animal will strongly determine GIT development. Conditions of catabolic stress 
may lead to (villus) atrophy, which is detrimental for the barrier function and increases the translocation of bacteria. McCauley et al. (1996) established a positive effect on total GIT weight and mucosa width of an increasing amount of rat feed offered in addition to parental feeding. Also, infection affects the functioning of the GIT as demonstrated by Nabuurs (1997) who compared GIT morphology in weaned littermates from groups with mortality, without mortality and free of pathogens. Such results indicate the interaction between mucosal morphology and development, and the microbial population in the lumen. A close relationship was suggested between the occurrence of diarrhoea and mucosa proliferation in weaned piglets.

\section{Collective term of 'endogenous loss'}

The term 'endogenous' is used as a collective term for the compounds which leave the SI with digesta, but which are not directly of feed origin. This fraction contains microbial material and material originating from the GIW that remained undigested in the SI. The lack of quantitative knowledge on the effect of GIW metabolism, of recycling between the GIW and lumen is seen as a major limitation to estimate the contribution of GIW metabolism to endogenous protein and to whole-animal AA metabolism (Reeds et al. 1999). Various experimental techniques are applied (for an extensive review, see Fuller \& Reeds, 1998). Measurements do indicate, however, that an important and highly variable part of ileal outflow of $\mathrm{N}$ is of endogenous origin (35 to $60 \%$ ). Physical and chemical characteristics of digesta are co-determinant for the rate and extent of hydrolysis of proteins and carbohydrates by digestive enzymes, and probably the same holds for endogenous compounds.

\section{Hormonal regulation and physiological status}

\section{Gastrointestinal tract growth}

Growth of the GIT is primarily driven by nutrient supply and GIT mass, and an adaptation of the GIT to enzymic $v$. fermentative digestion. Hormonal factors seem to have no regulatory function other than facilitating nutrient utilisation and GIT growth (Reeds et al. 1999). For example, ad libitum v. meal feeding exposes the GIT to different peak loads of digesta and nutrients. The highest load with meal feeding may result in a stronger endocrine regulation of nutrients fluxes, a heavier GIT, an increased nutrient utilisation by the GIT, and a lighter carcass (Dawson, 1999).

\section{Gastrointestinal tract as an endocrine organ}

The GIT is the largest endocrine organ of the body. There seems to be no clear distinction between the neuroendocrine and immune system of the GIW because of the many interactions (Shanahan, 1994) instead of clear independent functions of cytokines, growth factors, local hormones and peptides. Hormone-producing cells are located in the mucosa of the stomach, SI and LI. The physiological purpose of these gut hormones (incretins) is to adjust the capacity of digestion and to facilitate the endocrine regulation in peripheral tissues in relation to size and composition of the meal. Incretins modulate GIT functioning (kinetics of digestion), the sensation of saturation (via the central nervous system), and the efficiency of hormonally (insulin) regulated glucose, AA and fat metabolism by peripheral tissues of the body. The net result of incretins on nutrient utilisation by the GIT remains hard to quantify because of the multiple functions and targets and is probably highly dependent on diet composition and feeding strategy. There are indications that incretins have the potential to shift the utilisation of nutrients from arterial blood to the lumen (Deveney \& Way, 1986). Such a shift might have consequences for the type of nutrient utilised by the GIT. Incretins such as epidermal growth factor (Allen et al. 1993) affect mitosis in the mucosa. The regulatory role consists of the stimulation of cell proliferation and the initiation of repair mechanisms after damage to the mucosa of the stomach or duodenum, and inhibits the secretion of acid in the stomach.

\section{Gastrointestinal tract as target organ}

In normally fed and healthy animals, physiological concentrations of insulin, insulin-like growth factor 1 and growth hormone have no effect on growth and protein synthesis in the serosal and mucosal layer of the SI wall. Effects of these hormones only become apparent with extremely low concentrations in situations of prolonged fasting or with surgical stress when the GIT is in a catabolic state. A potential influence of prolactin, somatotropin and thyroid hormone on AA transport systems is mentioned, however (Rérat et al. 1991). In the case of prolactin this would mean that at the onset of lactation an adaptation of AA transport systems in the mucosa would occur, affecting the rate and extent of transport and metabolism of nutrients. This aspect may be of particular interest for nutritional requirements of lactating sows (and nursed piglets) and dairy cows in early lactation.

During infection or GIT trauma, cytokines and prostaglandins induce a state of anorexia with low feed intake and a reduced utilisation of nutrients by the GIT. During a stress response, the release of catecholamines leads to a reduced arterial blood supply to the GIT in favour of the brain. Longterm stress strongly reduces the metabolism of the GIT and continuation of this stress for a too long a period may cause damage to the GIT. Recovery from this damage leads to an increased nutrient utilisation by the GIT (Gruys et al. 1998) comparable with the compensatory growth observed in animals recovering from underfeeding.

Physiological concentrations of insulin are required for maintaining a normal protein synthesis in the mucosa of the SI. Shortage of insulin (type I diabetes) reduces the FPSR in mucosal cells by $30 \%$. For all effects of insulin on the GIT the assumption holds that a certain maintenance dose of insulin is necessary for a normal functioning of metabolism but that further stimulation by insulin is impossible (Charlton et al. 2000). There is no effect of growth hormone on enzymes in the SI that regulate the degradation of AA. The indirect effect (as with insulin) is that growth hormone reduces the AA concentrations in arterial blood and hence their arterial supply to the GIT (Bush et al. 2002). 
Glucocorticoids (cortisol) released with stress stimulate the intracellular breakdown of arginine and glutamine in enterocytes. Flynn \& Wu (1997) observed an increased appearance of metabolites of arginine and glutamine of $50 \%$ or more when pharmacological doses of cortisol were applied. Under more physiological conditions (long-term stress) similar effects are expected.

\section{Net nutrient fluxes in portal blood}

A combined measurement of feed digestion and net portal fluxes of nutrients delivers insight into the nutrient supply to (via lumen and arterial blood) and the nutrient utilisation by the PDV. Higher nutrient concentrations in portal blood than in arterial blood indicate net appearance of that nutrient (MacDonald, 1999). The dietary source of glucose and AA determines the kinetics and extent of digestion and the percentages of these nutrients appearing in portal blood. There are indications of interactions between glucose and AA and among individual AA in their utilisation by the GIW (Van der Meulen \& Jansman, 1997). Furthermore, nutrient appearance in portal blood depends on the site and extent of digestion in the GIT and the kinetics of absorption (Jansman et al. 1997). As well as the GIW, visceral fat tissue also influences the apparent nutrient utilisation by the PDV. The weight of visceral fat in dairy cows, for example, varies substantially depending on the stage of lactation (Baldwin, 1995).

Net portal fluxes of nutrients indicate the net nutrient utilisation or appearance, whereas measurement of unidirectional fluxes by isotopic techniques gives more information on the mechanisms involved. Stoll et al. (1999) observed in piglets that the first-pass utilisation by the PDV of nutrients supplied by arterial blood and from the lumen was 7 and $6 \%$ for glucose and 20 and $94 \%$ for glutamine, and contributed to $15,29,19$ and $36 \%$ of the production of $\mathrm{CO}_{2}$ by the PDV, respectively, and to $75 \%$ of the total apparent energy requirement of the PDV. Glucose supplied from the lumen contributed to 18 and $31 \%$ of the portal appearance of alanine and lactate. Furthermore, roughly a third of the supply of EAA from the lumen was utilised by the PDV on first pass through the GIW $(35,32,35$ and $61 \%$ for lysine, leucine, phenylalanine and threonine). For most EAA the PDV utilisation of the arterial supply covered $75 \%$ or more of the total utilisation. Only 12 to $21 \%$ of the total utilisation was retrieved as mucosal protein, suggesting that EAA catabolism played a much more important role than incorporation in proteins.

The fate of AA supplied by arterial blood and from the lumen strongly varies (Burrin \& Reeds, 1997). Although the arterial supply of AA seems most important for nutrition of the GIW, a radical atrophy occurs when nutrition from the luminal side is absent. This may relate to the lack of nutrient supply from the lumen, but is probably also the consequence of inactivity of the GIT due to absence of digesta. The presence of nutrients in the lumen is a strong stimulus for GIT growth (Reeds et al. 1999). Brush-border enzymes are thought to be synthesised preferentially from AA supplied from the lumen, whereas enterocytes in crypts preferentially use AA supplied by arterial blood. For mucus synthesis, existence of a preference is unclear.
Upon differentiation and ageing of enterocytes during their migration from crypt to villus tip, they obtain the capacity to utilise nutrients supplied from the lumen. This implies that the source of AA for protein synthesis depends on the type of cells involved and their functioning. This remains hard to verify, however, as long as combined measurements of specific functions of the GIW and of unidirectional fluxes of AA are lacking.

Similar to pigs, also in ruminants substantial utilisation occurs of nutrients supplied by arterial blood, in particular of VFA. The fraction of VFA produced in the GIT that appears in portal blood is therefore a clear overestimation of the extent of metabolism during transport from rumen to blood.

Huntington et al. (1983) and Kristensen et al. (1996a,b) reported $31-35 \%$ utilisation of acetate at low rates of supply by arterial blood. The rate of acetate utilisation increased with arterial supply but eventually saturated at about $20 \%$ of the supply rate. Acetate may be an important energy source for the GIW and also for visceral fat. There are indications of acetate and butyrate utilisation for de novo lipogenesis in epithelial cells (Zambell et al. 2003). Besides acetate, PDV utilises butyrate and $\beta-\mathrm{OH}$-butyrate (Kristensen et al. 1999) and large quantities of $\beta-\mathrm{OH}$-butyrate become available from butyrate metabolism during transport from the rumen to portal blood (Rémond et al. 1995).

\section{Net portal fluxes in pigs}

Glucose. The effect of the kinetics of starch digestion on the percentage of this starch appearing in portal blood as glucose seems consistent. A compilation of six experiments using growing pigs, presented in Table 5, indicates that a lower percentage of digested starch is recovered as a net portal flux of glucose when starch digestion is slower. Besides the type of starch source, also the PDV mass may affect the percentage of starch retrieved as glucose in portal blood. Assuming that GIT weight is correlated with pig weight, the results indicate that the fraction of digested starch appearing as net portal flux of glucose is larger in lighter pigs (experiments 1 and 2) compared with heavier pigs (experiments 3 and 4). In experiments 1 and 2 a larger proportion of maize starch consumed was recovered as net portal flux of glucose than in experiments 3 and 4 . Differences among experiments are small and hence not conclusive.

Part of the differences in the portal appearance of glucose can be related back to lactate formation. In experiment 1 (Table 5) about $20 \%$ of the apparent glucose utilisation by the PDV was attributed to lactate formation and in experiment 2 it was established that a higher PDV utilisation of glucose was accompanied by less lactate formation. It seems, therefore, that lactate is not a main explanation of variation in glucose metabolism by the PDV.

Protein. Small peptides as well as free AA may be transported into cells (Webb \& Bergman, 1991), but probably the main part of these peptides is hydrolysed by the GIW and enters metabolism or appears in portal blood as free AA. The dietary source of digestible protein influences the kinetics of protein digestion and AA absorption, and 


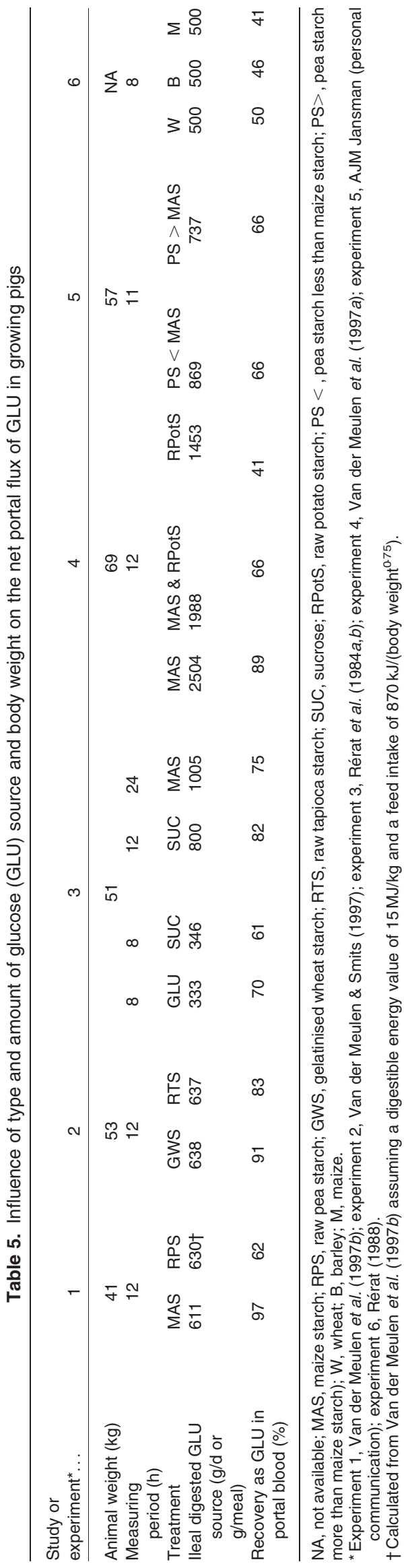

thereby the type and the quantity of AA appearing in portal blood. Seven experiments are summarised in Table 6 and demonstrate that generally the percentage of ileal digested protein recovered as net portal flux of AA decreased with a slower protein digestibility. In experiment 9 the low protein content of the diet probably was responsible for a recovery percentage below $50 \%$. Effects of body weight on PDV AA utilisation were not consistent (Table 6). The results suggest that with a slower protein digestibility the utilisation of AA by PDV intensifies, and that the presence of glucose has a sparing effect on AA metabolism.

Apart from the source of protein, the amount of ileal digestible protein is also a major determinant of the recovery of AA in portal blood. In experiment 6 the amount of a single protein source was varied and it indicated that recovery reduces with an increased amount of AA digested. However, other dietary conditions or protein sources might lead to different results.

AA metabolism by the GIW is not limited to NEAA because it has been shown that extensive catabolism of EAA occurs (Windmueller \& Spaeth, 1980). Intragastric infusions of EAA in piglets of age $28 \mathrm{~d}$ led to a recovery of $56 \%$ of these AA in portal blood (Stoll et al. 1998). Table 7 shows the appearance of total, EAA and NEAA recovery for the experiments presented in Table 6. It appears that there is an extensive utilisation of glutamine and glutamate reflected by negative apparent appearances of glutamine and glutamate in portal blood when expressed as a percentage of the ileal digested amounts. Of the EAA, an average of $75 \%$ of lysine, leucine and phenylalanine is recovered in portal blood. This implies that a net $25 \%$ of the amounts absorbed from the lumen is metabolised, which is lower than the $35 \%$ estimated by Stoll et al. (1998) for piglets. The utilisation of EAA seems to decrease with age, and PDV and GIT weight.

Fermentable carbohydrates. Fermentable carbohydrates in pig diets stimulate an intensive microbial fermentation in the LI, and to some extent in the SI. Lactate is produced in the proximal part of the intestine (stomach and SI) whereas VFA are the principal products in the LI (Bakker, 1995). The fermentation capacity of the LI is substantial (Bakker, 1995), whereas that of the SI seems limited.

In experiment 5 (Table 5) $25 \%$ of digestible maize starch and slowly fermentable cellulose was replaced by wellfermentable beetpulp and wheat middlings. Roughly, the portal appearance of VFA and lactate doubled, and substantial shifts occurred in the type of VFA released (acetate, from 65 to $53 \%$; propionate, from 30 to $39 \%$; butyrate, from 5 to $8 \%$ ). The increased rate of butyrate synthesis might have consequences for the metabolic activity and proliferation of epithelial tissues and the nutrient requirements of the GIW. Replacement of maize starch by potato starch in experiment 4 (Table 5) increased butyrate but not propionate. Studies by Rérat (1996) showed a tendency to increased propionate formation with feeding increased amounts of fermentable carbohydrate to pigs. Despite similar amounts of glucose digested, a lower percentage was recovered in portal blood with a stimulation of microbial fermentation and increasing VFA yields. Rérat (1996) concluded that the contribution of VFA to the energy metabolism of the pig remains limited to some 2 to $6 \%$ and 


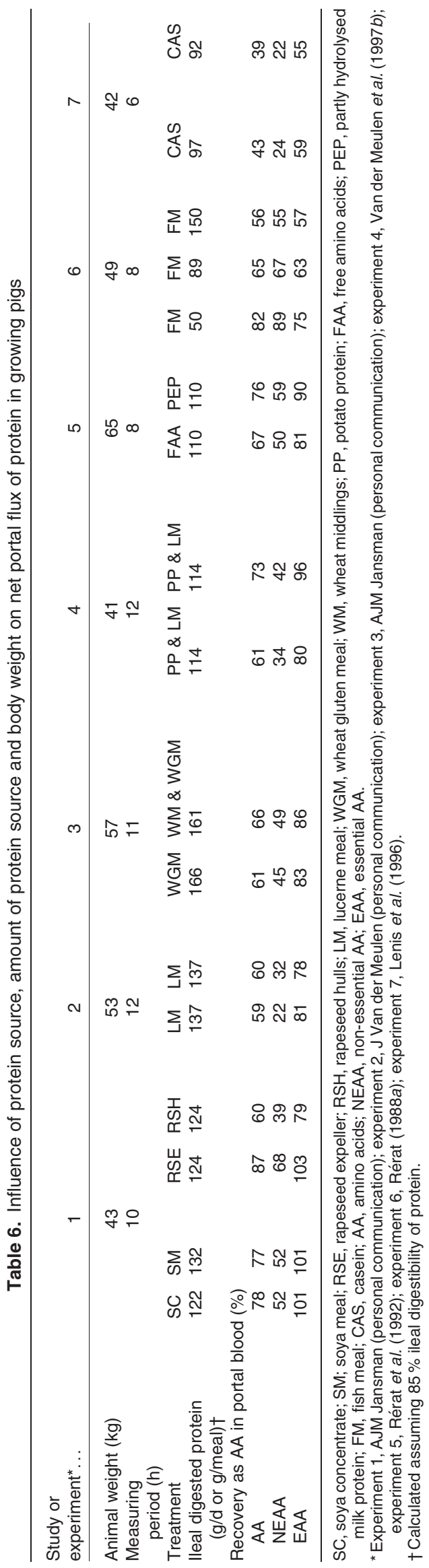

does not compensate for the reduced contribution of glucose ( 5 to $10 \%$ reduction in metabolisable energy with 6 to $16 \%$ fermentable carbohydrates in dietary DM). These results suggest that a substantial increase in PDV utilisation of VFA occurs when carbohydrate fermentation in the GIT is stimulated.

Interactions between glucose, amino acids and volatile fatty acids. It is often emphasised that there are strong interactions between AA, glucose and VFA concerning their supply to the PDV, the extent of their utilisation by the PDV and their net appearance in portal blood. Experimental results of Rérat (1988, 1996) and Rérat et al. (1992) support the existence of such interactions. In the absence of carbohydrates, AA appear much faster in portal blood, independent of the form these AA are supplied to the GIT. The presence of carbohydrates retards the appearance of infused AA up to $5 \mathrm{~h}$. There is competitive inhibition among glucose and AA and among individual AA for their transport by carriers (Vinardell, 1990). These processes are enzymically driven and the competitive inhibition is concentration dependent as described for amino transport by the udder by Maas et al. (1998). Since the capacity to transport glucose and AA varies with the site in the GIT, a distinction between duodenum, jejunum and ileum seems necessary (Rérat et al. 1988b). In this respect, the variation in the kinetics of digestion of starch and protein sources is of importance as well. Measurements in portal blood indicate that in general glucose appears faster than AA (maximal glucose and AA flux within 1 and $2-6 \mathrm{~h}$ after a meal; experiments 4 and 5).

\section{Net portal fluxes in ruminants}

Glucose. The fraction of starch, resistant to rumen fermentation and digested in the SI, that is recovered as a net portal flux of glucose in growing beef steers ranges from 0.3 to 0.7 (Reynolds et al. 1997; Kreikemeier et al. 1991; Kreikemeier \& Harmon, 1995). The results of these studies indicate that a larger amount of digested starch increases the appearance of glucose in portal blood as well. Other studies confirm this, however, and even demonstrated a net glucose uptake by the PDV (Lozano et al. 2000). In lactating cows, the net portal flux of glucose is limited or negative (Huntington \& Reynolds, 1986; Reynolds et al. 1988). Experimental evidence of ruminants is inconclusive whether the post-rumen digestion of starch may lead to a substantial increase in net portal appearance of glucose. Although methodological problems may have contributed to the inconsistent results reported in the literature, it seems that under a wide range of diets and physiological conditions there may be a net uptake of glucose by the PDV despite large quantities of starch offered to the SI (Reynolds et al. 1997). Glucose utilised by the PDV may be absorbed from the lumen or supplied by arterial blood. With infusions of starch in the abomasum Harmon et al. (2001) established a $132 \%$ increase in the utilisation of glucose supplied by arterial blood, which was equivalent to $20 \%$ of the total amount of glucose units infused. There is still doubt whether the PDV or GIW in ruminants has a similar preference for utilisation of glucose from arterial blood under various 
Table 7. Portal appearance of individual amino acids $(\mathrm{AA})$ in the pig trials presented in Table 6

\begin{tabular}{|c|c|c|c|c|c|c|c|c|c|c|c|c|c|c|c|c|}
\hline \multirow{2}{*}{$\begin{array}{l}\text { Study or } \\
\text { experiment*... } \\
\text { Treatment }\end{array}$} & \multicolumn{4}{|c|}{1} & \multicolumn{2}{|c|}{2} & \multicolumn{2}{|r|}{3} & \multicolumn{2}{|c|}{4} & 5 & \multicolumn{3}{|c|}{6} & \multicolumn{2}{|c|}{7} \\
\hline & SC & SM & RSE & RSM & LM & LM & WGM & WM \& WGM & PP \& LM & PP \& LM & FAA & FM & FM & $\mathrm{FM}$ & CAS & CAS \\
\hline $\begin{array}{l}\text { Ileal digested protein } \\
\text { (g/d or } \mathrm{g} / \mathrm{meal}) \dagger \\
\text { Uleal digested } \mathrm{AA}(\%)\end{array}$ & 122 & 132 & 124 & 124 & 137 & 137 & 166 & 161 & 114 & 114 & 110 & 50 & 89 & 150 & 97 & 92 \\
\hline Lys & 89 & 105 & 95 & 67 & 79 & 87 & 86 & 84 & 83 & 109 & 69 & 59 & 56 & 54 & 53 & 57 \\
\hline Met & & & & & 51 & 56 & 86 & 78 & 93 & 99 & 95 & 61 & 57 & 56 & 53 & 57 \\
\hline Met + Cys & 69 & 69 & 88 & 64 & & & & & & & & & & & & \\
\hline Cys & & & & & 74 & 44 & - & - & 77 & 108 & - & 94 & 55 & 36 & 41 & 43 \\
\hline Thr & 111 & 92 & 111 & 106 & 69 & 19 & 66 & 86 & 44 & 59 & 52 & 78 & 64 & 56 & 43 & 46 \\
\hline Trp & 90 & 88 & 96 & 75 & - & - & - & - & 74 & 111 & - & - & - & - & 82 & 63 \\
\hline $\mathrm{lle}$ & 108 & 105 & 106 & 69 & 64 & 70 & 79 & 88 & 83 & 98 & 69 & 84 & 65 & 55 & 58 & 56 \\
\hline Arg & 102 & 102 & 134 & 103 & 79 & 91 & 109 & 99 & 109 & 124 & 92 & 42 & 46 & 48 & 95 & 80 \\
\hline Phe & 99 & 110 & 95 & 88 & 59 & 69 & 69 & 69 & 95 & 107 & 72 & 79 & 77 & 76 & 58 & 48 \\
\hline His & 108 & 112 & 112 & 72 & 79 & 78 & 96 & 94 & 108 & 127 & - & 89 & 65 & 53 & 64 & 64 \\
\hline Leu & 110 & 107 & 95 & 73 & 57 & 66 & 72 & 81 & 86 & 99 & 80 & 83 & 66 & 57 & 47 & 47 \\
\hline Tyr & 113 & 132 & 93 & 67 & 75 & 89 & 75 & 82 & 86 & 100 & 50 & 122 & 91 & 75 & 65 & 52 \\
\hline Val & 102 & 97 & 97 & 79 & 78 & 43 & 88 & 112 & 67 & 84 & 102 & 84 & 66 & 57 & 53 & 48 \\
\hline Ala & 231 & 278 & 253 & 166 & 177 & 180 & 288 & 303 & 193 & 216 & 215 & 202 & 154 & 129 & 235 & 253 \\
\hline Aspx & 50 & 47 & 54 & 38 & 39 & 46 & 98 & 84 & 49 & 47 & 28 & 41 & 34 & 30 & 40 & 46 \\
\hline Glu & & & & & & & & & & & 18 & & & & & \\
\hline Glnx & -22 & -37 & -8 & -39 & -130 & -98 & -2 & -5 & -187 & -178 & & 17 & 10 & 6 & -30 & -40 \\
\hline Gln & & & & & & & & & & & -8 & & & & & \\
\hline Gly & 136 & 133 & 85 & 100 & 51 & 49 & 103 & 160 & 68 & 74 & 80 & 91 & 69 & 57 & 83 & 83 \\
\hline Pro & 74 & 79 & 133 & 90 & 47 & 63 & 56 & 72 & 48 & 57 & 68 & 79 & 67 & 62 & 39 & 30 \\
\hline Ser & 92 & 103 & 101 & 80 & 60 & 61 & 83 & 93 & 94 & 102 & 71 & 76 & 65 & 60 & 64 & 76 \\
\hline
\end{tabular}

SC, soya concentrate; SM, soya meal; RSE, rapeseed expeller; RSM, rapeseed meal; LM, lucerne meal; WGM, wheat gluten meal; WM, wheat middlings; PP, potato protein; FAA, free AA; FM, fish meal; CAS, casein Experiment 1, AJM Jansman (personal communication); experiment 2, J Van der Meulen (personal communication); experiment 3, AJM Jansman (personal communication); experiment 4, Van der Meulen et al. (1997b); experiment 5, Rerat et al. (1992); experiment 6, Rerat (1988a); experiment 7, Lenis et al. (1996).

† Calculated assuming $85 \%$ ileal protein digestibility. 
Table 8. Disappearance from the gastrointestinal tract and the appearance $(\mathrm{g} / \mathrm{d})$ of essential amino acids (EAA), non-essential amino acids (NEAA), total amount of amino acids (TAA) in the mesenteric vein (MDV) and portal vein (PDV) and in milk of dairy cows (after Berthiaume et al. 2001)

\begin{tabular}{lcrrr}
\hline & & \multicolumn{3}{c}{ Appearance } \\
\cline { 3 - 5 } Amino acid & $\begin{array}{c}\text { Disappearance from } \\
\text { gastrointestinal tract }\end{array}$ & MDV & PDV & Milk \\
\hline Arg & 80 & 82 & 50 & 20 \\
His & 24 & 30 & 22 & 15 \\
Ile & 82 & 84 & 51 & 33 \\
Leu & 128 & 118 & 80 & 54 \\
Lys & 108 & 83 & 60 & 45 \\
Met & 36 & 37 & 24 & 15 \\
Phe & 70 & 70 & 53 & 27 \\
Thr & 65 & 75 & 28 & 26 \\
Val & 78 & 86 & 40 & 37 \\
Total EAA & 670 & 663 & 408 & 271 \\
Ala & 88 & 103 & 70 & 19 \\
Asp & 153 & 4 & 13 & 23 \\
Cys & 15 & 4 & -24 & 5 \\
Glu & 191 & 21 & 16 & 67 \\
Gly & 89 & 51 & 38 & 11 \\
Pro & 65 & 32 & 6 & 55 \\
Ser & 58 & 72 & 44 & 31 \\
Asn & - & 56 & 30 & 19 \\
Cit & - & 33 & 16 & - \\
Orn & - & 38 & -36 & 52 \\
Tau & - & 1 & 10 & - \\
Tyr & - & 72 & 45 & 28 \\
Total NEAA & 659 & 1164 & 657 & 582 \\
TAA & 1329 & & & 311 \\
\hline & & 501 & 249 &
\end{tabular}

circumstances as observed in pigs. Furthermore, the portal retrieval of glucose always seems higher with abomasal infusions of glucose than with starch (Huntington \& Reynolds, 1986), which can be explained by the extensive and fast absorption of glucose in the proximal duodenum and the need to digest starch first before glucose can be absorbed in the jejunum and ileum (Reynolds et al. 1997). In this respect, variation in the kinetics and the site of starch digestion and glucose absorption affects the regulation mechanisms of glucose utilisation by the PDV (GIW and visceral fat) and, as a result, causes variation in the fraction of digested starch recovered as glucose in portal blood.

Protein. Intestinal digestion of feed proteins resistant to rumen fermentation may affect the profile of AA absorbed to portal blood. However, the main part of protein digested in the SI is of microbial origin and this has a less variable AA composition than feed protein (Reynolds et al. 1997). The supply of digestible AA to the intestine of ruminants depends more on the amount of microbial protein synthesised in the rumen than on feed protein resistant to rumen fermentation, and basic elements to predict microbial protein synthesis in the rumen are well defined (Dijkstra et al. 2002). Recovery of EAA, NEAA and total AA absorbed from the intestine in lactating cows as a net portal flux was 61, 38 and 49\% (Berthiaume et al. 2001; Table 8). Net mesenteric fluxes were 62, 102 and $77 \%$ higher than net portal fluxes, indicating that tissues of the stomachs and the intestines utilised similar amounts of AA. Predominantly glutamine, glutamate and aspartate are utilised by enterocytes (Britton \& Krehbiel, 1993). Other in vivo observations indicate the effects of nutritional factors on AA utilisation by tissues of the stomachs (diet specificity; Reynolds \& Huntington, 1988a) and by the PDV (effects of VFA; Krehbiel et al. 1992; Nozière et al. 2000; Gross et al. $1990 a$ ). In an overview of several in vivo trials, Huntington (1990) suggested that less than $50 \%$ of AA absorbed is utilised by the PDV in lactating cows, about 50 to $60 \%$ in heifers, and 60 to $75 \%$ in steers.

Volatile fatty acids. The net flux of VFA appearing in portal blood strongly depends on VFA production rates in the rumen. Studies in which VFA supply was varied by intraruminal infusions demonstrated that a considerable fraction of this supply is not retrieved as a net portal flux of VFA. Infused acetate in dry cows (Huntington et al. 1983), propionate in steers (Seal \& Parker, 1994) and butyrate in steers (Krehbiel et al. 1992) was recovered as a net portal flux for 69,78 and $40 \%$ (in the latter case $26 \%$ as butyrate and $14 \%$ as $\beta$-OH-butyrate). These observations on VFA utilisation by the PDV deviate from the general estimates of 70,50 and $10 \%$ for acetate, propionate and butyrate as presented in reviews (Bergman, 1990; Bugaut, 1987). These differences illustrate that the fraction of VFA recovered as net portal flux varies strongly with nutritional conditions and status of the GIW (Bergman, 1990; Britton \& Krehbiel, 1993), which has already been discussed (Table 3). Again, it is unlikely that a constant fraction of VFA produced in the GIT is utilised by the PDV over a wide range of nutritional and physiological conditions (Bannink et al. 2000). For 
accurate estimates of gluconeogenesis in a lactating cow, accurate estimates of the propionate flux are important, however, and estimates of Bergman (1990) seem inapplicable for that purpose.

Interactions between glucose, amino acids and volatile fatty acids. Intermediary metabolism in ruminants is driven more strongly by VFA than that in single-stomached animals. The competition between nutrients for utilisation by the PDV and GIW implies that with changes in the intraluminal and arterial concentrations of glucose, AA and VFA the intracellular concentrations and the preference for the utilisation of specific nutrients by the GIW might change. When identifying the interactions between nutrients, GIT compartments exposed to large and small amounts of VFA have to be distinguished. Metabolic activity of tissues in the wall of the forestomachs and the LI depend heavily on VFA for their energy requirement, tissues in the wall of the SI on glucose and AA, and visceral fat on acetate. With combined measurements of the net portal and net mesenteric fluxes it becomes apparent that the SI utilises large amounts of glucose (Reynolds \& Huntington, $1988 a, b$ ) as well as AA (Reynolds \& Huntington, $1988 a, b$; Berthiaume et al. 2001). Whether kinetics of digestion, nutrient absorption and arterial nutrient supply to the GIW have similar implications on the nutrient preference by the PDV, as discussed for single-stomached animals, needs further investigation.

\section{Conclusions}

Physiological and metabolic functions of the GIT affect nutrient requirement of the GIW and therefore it is necessary to quantify and model GIT functioning to predict nutrient supply from diets to peripheral and productive organs. As an organ with multiple compartments and physiological functions, the GIT strongly adapts to varying nutritional and physiological conditions with high metabolic costs. The impact of GIW metabolism on whole-body metabolism is profound with respect to protein turnover, ion transport, and costs of the immune response of the animal. The relative contribution of each of these functions or processes, as well as that of mucus and enzyme secretions, depends on the nutritional and physiological state of the GIT and may change strongly with changed conditions. For an improved quantification of the metabolic activity of the GIW, the kinetics need to be studied of the digestive processes, of the intraluminal microbial activity, of the absorption of nutrients, of the arterial supply of nutrients, and of the specific metabolic functions of the GIW. Compartments of the GIT with their own specialised functions need to be distinguished. Under suboptimal circumstances such as infections, or with strongly varying nutritional conditions, nutrient utilisation by the GIW may be extensive compared with whole-body nutrient utilisation. A modelling approach seems indispensable to delineate the complexity of interactions between GIW functioning and nutrient metabolism by the GIW.

\section{Acknowledgements}

The present review was partly financed by the Dutch Commodity Board of Feedstuffs.

\section{References}

Allen A, Flemstrom G, Garner A \& Kivilaakso E (1993) Gastroduodenal mucosal protection. Physiological Reviews 73, $823-857$.

Alverdy JC (1990) Effects of glutamine-supplemented diets on immunology of the gut. Journal of Parenteral and Enteral Nutrition 14, 109S-113S.

Ash R \& Baird GD (1973) Activation of volatile fatty acids in bovine liver and rumen epithelium. Biochemical Journal 136, $311-319$.

Bakker GCM (1995) Interaction between carbohydrates and fat in pigs. Impact on energy evaluation in feeds. $\mathrm{PhD}$ Thesis, Wageningen Agricultural University, Wageningen, The Netherlands.

Baldwin RL (1995) Modeling Ruminant Digestion and Metabolism. London: Chapman \& Hall.

Baldwin RL \& Jesse BW (1996) Propionate modulation of ruminal ketogenesis. Journal of Nutrition 122, 1149-1153.

Bannink A, Dijkstra J, Kebreab E \& France J (2006a) Advantages of a dynamical approach to rumen function to help resolve environmental issues. In Nutrient Digestion and Utilisation in Farm Animals: Modelling Approaches, pp. 281-298 [E Kebreab, J Dijkstra, J France, A Bannink and WJJ Gerrits, editors]. Wallingford, UK: CAB International.

Bannink A, Kogut J, Dijkstra J, France J, Tamminga S \& Van Vuuren AM (2000) Modelling production and portal appearance of volatile fatty acids in cows. In Modelling Nutrient Utilisation in Farm Animals, pp. 87-102 [JP McNamara, $\mathrm{J}$ France and DE Beever, editors]. Wallingford, UK: CAB International.

Bannink A, Kogut J, Dijkstra J, Kebreab E, France J, Tamminga S \& Van Vuuren AM (2006b) Estimation of the stoichiometry of volatile fatty acid production in the rumen of lactating cows. Journal of Theoretical Biology 238, 36-51.

Bardocz S, White A, Grant G, Walker TJ, Brown DS \& Pusztai A (2001) The role of polyamines in intestinal function and gut maturation. In Gut Environment of Pigs, pp. 29-42 [A Piva, KE Bach-Knudsen and JE Lindberg, editors]. Nottingham, UK: University Press.

Bedford MR (1996) Interaction between ingested feed and the digestive system in poultry. Journal of Applied Poultry Research 5, 86-95.

Bergman EN (1990) Energy contributions of volatile fatty acids from the gastrointestinal tract in various species. Physiological Reviews 70, 567-590.

Berthiaume R, Dubreuil P, Stevenson M, McBride BW \& Lapierre $H$ (2001) Intestinal disappearance and mesenteric and portal appearance of amino acids in dairy cows fed ruminally protected methionine. Journal of Dairy Science 84, 194-203.

Bertolo RFP, Chen CZL, Pencharz PB \& Ball RO (1999) Small intestinal atrophy has a greater impact on nitrogen metabolism than liver bypass in piglets fed identical diets via gastric, central venous or portal venous routes. Journal of Nutrition $\mathbf{1 2 9}$, $1045-1052$.

Bertolo RFP, Pencharz PB \& Ball RO (2000) Organ and plasma amino acid concentrations are profoundly different in piglets fed identical diets via gastric, central venous or portal venous routes. Journal of Nutrition 130, 1261-1266.

Biagi G, Piva A, Hill T, Schneider DK \& Crenshaw TD (2003) Low buffering capacity diets with added organic acids as a substitute 
for antibiotics in diets for weaned pigs. In Proceedings of the 9th International Symposium on Digestive Physiology in Pigs, pp. 217-219 [RO Ball, editor]. Banff, AB, Canada: University of Alberta.

Britton R \& Krehbiel C (1993) Nutrient metabolism by gut tissues. Journal of Dairy Science 76, 2125-2131.

Brunsgaard G, Eggum BO \& Sandström B (1995) Gastrointestinal growth in rats as influenced by indigestible polysaccharides and adaptation period. Comparative Biochemistry and Physiology 111A, 369-377.

Buddington RK (1998) The influence of dietary inputs on the neonatal gastrointestinal tract: managing the development of a complex system. Journal of Animal Feed Science 7, 155-165.

Bueno J, Torres M, Almendros A, Carmona R, Nuñez MC, Rios A \& Gil A (1994) Effect of dietary nucleotides on small intestinal repair after diarrhoea. Histological and ultrastructural changes. Gut 35, 926-933.

Bugaut M (1987) Occurrence, absorption and metabolism of short chain fatty acids in the digestive tract of mammals. Review. Comparative Biochemistry and Physiololgy 86B, 439-472.

Burrin DG \& Reeds PJ (1997) Alternative fuels in the gastrointestinal tract. Gastroenterology 13, 165-170.

Burrin DG, Stoll B, Jiang RH, Chang XY, Hartmann B, Holst JJ, Greeley GH Jr \& Reeds PJ (2000) Minimal enteral nutrient requirements for intestinal growth in neonatal piglets: how much is enough? American Journal of Clinical Nutrition 71, 1603-1610.

Bush JA, Wu G, Suryawan A, Nguyen HV \& Davis TA (2002) Somatotropin-induced amino acid conservation in pigs involves differential regulation of liver and gut urea cycle enzyme activity. Journal of Nutrition 32, 59-67.

Chang EB \& Rao MC (1994) Intestinal water and electrolyte transport. Mechanisms of physiological and adaptive responses. In Physiology of the Gastrointestinal Tract, 3rd ed.,pp. 2027-2075 [LR Johnson, editor]. New York: Raven Press Ltd.

Charlton M, Ahlman B \& Nair KS (2000) The effect of insulin on human small intestinal mucosal protein synthesis. Gastroenterology 118, 299-306.

Dawson JM (1999) Variation in nutrient supply and effect on whole body anabolism. In Proceedings of the 8th International Symposium on Protein Metabolism and Nutrition, EAAP Publication no. 96, pp. 101-126 [GE Lobley, A White and JC MacRae, editors]. Wageningen, The Netherlands: Wageningen Pers.

Deveney CW \& Way LW (1986) Regulatory peptides of the gut. In Basic \& Clinical Endocrinology, 2nd ed., pp. 501-522 [FS Greenspan and PH Forsham, editors]. Los Altos, CA: Lange Medical Publications.

Dijkstra J, Boer H, Van Bruchem J, Bruining M \& Tamminga S (1993) Absorption of volatile fatty acids from the rumen of lactating dairy cows as influenced by volatile fatty acid concentration, $\mathrm{pH}$ and rumen liquid volume. British Journal of Nutrition 69, 385-396.

Dijkstra J, Forbes JM \& France J (2005) Quantitative Aspects of Ruminant Digestion and Metabolism, 2nd ed. Wallingford, UK: CAB International.

Dijkstra J, Mills JAN \& France J (2002) The role of dynamic modelling in understanding the microbial contribution to rumen function. Nutrition Research Reviews 15, 67-90.

Dirksen G, Liebich HG, Brosi G, Hagemeister H \& Mayer E (1984) Morphologie der pansenschleimhaut und fettsaureresorption beim Rind- bedeutende faktoren fur gesundheit und Leistung (Morphology of the rumen mucosa and fatty acid absorption in cattle-important factors for health and production). Zentralblatt fur Veterinarmedizin 31A, 414-430.

Dugan MER, Knabe DA \& Wu G (1994) Glutamine and glucose metabolism in intraepithelial lymphocytes from pre- and postweaning pigs. Comparative Biochemistry and Physiology 109B, 675-681.
Edwards CA, Johnson IT \& Read NW (1988) Do viscous polysaccharides slow absorption by inhibiting diffusion or convection? European Journal of Clinical Nutrition 42, 307-312.

Ewtushik AL \& Ball RO (1998) Performance and intestinal development of early-weaned piglets receiving diets supplemented with selected amino acids and polyamines. In 1998 Ontario Swine Research Review, pp. 34-37. Guelph, Canada: Ontario Agricultural College.

Fengler AI \& Marquardt RR (1988) Water soluble pentosans from rye: II Effects on rate of dialysis and on the retention of nutrients by the chick. Cereal Chemistry 65, 298-302.

Fleming SE, Zambell KL \& Fitch MD (1997) Glucose and glutamine provide similar proportions of energy to mucosal cells of rat small intestine. American Journal of Physiology 273, G968-G978.

Flemström G \& Isenberg JI (2001) Gastroduodenal mucosal alkaline secretion and mucosal protection. News in Physiological Sciences 16, 23-28.

Flynn NE \& Wu G (1997) Glucocorticoids play an important role in mediating the enhanced metabolism of arginine and glutamine in enterocytes of postweaning pigs. Journal of Nutrition 127, 732-737.

Forstner JF \& Forstner GG (1994) Gastrointestinal mucus. In Physiology of the Gastrointestinal Tract, 3rd ed., pp. 1255-1283 [LR Johnson, DH Alpers, J Christensen, ED Jacobson and JH Walsh, editors]. New York: Raven Press.

Fuller MF \& Reeds PJ (1998) Nitrogen cycling in the gut. Annual Review of Nutrition 18, 385-411.

Gäbel G, Aschenbach JR \& Müller F (2002) Tranfer of energy substrates across the ruminal epithelium: implications and limitations. Animal Health Research Reviews 3, 15-30.

Galfi P, Neogrady S \& Sakata T (1991) Effects of volatile fatty acids on the epithelial cell proliferation of the digestive tract and its hormonal mediation. In Physiological Aspects of Digestion and Metabolism in Ruminants. Proceedings of the 7th International Symposium on Ruminant Physiology, pp. 49-59 [T Tsuda, Y Sasaki and R Kawashima, editors]. San Diego, CA: Academic Press.

Gaskins HR (2003) The commensal microbiota and development of mucosal defense in the mammalian intestine. In Proceedings of the 9th International Symposium on Digestive Physiology in Pigs, 1: Invited Reviews, pp. 57-71 [RO Ball, editor]. Banff, AB, Canada: University of Alberta.

Gerrits WJJ, Dijkstra J \& France J (1997) Description of a model integrating protein and energy metabolism in preruminant calves. Journal of Nutrition 127, 1229-1242.

Gill M, France J, Summers M, McBride BW \& Milligan LP (1989) Simulation of the energy costs associated with protein turnover and $\mathrm{Na}^{+}, \mathrm{K}^{+}$transport in growing lambs. Journal of Nutrition 119, $1287-1299$.

Goddeeris BM, Boersma WJA, Cox E, Van der Stede Y, Koenen ME, Vancaeneghem S, Mast J \& Van den Broeck W (2002) The porcine and avian intestinal immune system and its nutritional modulation. In Nutrition and Health of the Gastrointestinal Tract, pp. 97-134 [MC Blok, HA Vahl, L De Lange, AE Van de Braak, G Hemke and M Hessing, editors]. Wageningen, The Netherlands: Wageningen Academic Publishers.

Gross KL, Harmon DL \& Avery TB (1990a) Portal-drained visceral flux of nutrients in lambs fed alfalfa or maintained by total intragastric infusion. Journal of Animal Science 68, $214-221$.

Gross KL, Harmon DL, Minton JE \& Avery TB (1990b) Effects of isoenergetic infusions of propionate and glucose on portaldrained visceral nutrient flux and concentrations of hormones in lambs maintained by total gastric infusion. Journal of Animal Science 68, 2566-2574. 
Gruys E, Toussaint MJM, Landman WJM, Tivapasi M, Chamanza R \& Van Veen L (1998) Infection, inflammation and stress inhibit growth. Mechanisms and non-specific assessment of the processes by acute phase proteins. In Production Diseases in Farm Animals, 10th International Conference, pp. 72-87 [T Wensing, editor]. Wageningen, The Netherlands: Wageningen Pers.

Hall JC, Heel K \& McCauley R (1996) Glutamine. British Journal of Surgery 83, 305-312.

Harmon DL, Gross KL, Krehbiel CR, Kreikemeijer KK, Bauer ML \& Britton RA (1991) Influence of dietary forage and energy intake on metabolism and acyl-CoA synthetase activity in bovine ruminal epithelial tissue. Journal of Animal Science 69, 4117-4127.

Harmon DL, Richards CJ, Swanson KC, Howell JA, Matthews JC, True AD, Huntington GB, Gahr SA \& Russell RW (2001) Influence of ruminal or postruminal starch on visceral glucose metabolism in steers. In Energy Metabolism in Animals. Proceedings of the 15th Symposium of Energy Metabolism of Animals, EAAP Publication no. 103, pp. 273-276 [A Chwalibog and $\mathrm{K}$ Jakobsen, editors]. Wageningen, The Netherlands: Wageningen Pers.

Harada E, Niiyama M \& Syuto B (1986) Comparison of pancreatic exocrine secretion via endogenous secretin by intestinal infusion of hydrochloric acid and monocarboxylic acid in anesthetized piglets. Japanese Journal of Physiology 36, $843-856$.

Houle VM, Schroeder EA, Odle J \& Donovan SM (1997) Small intestinal disaccharidase activity and ileal villus height are increased in piglets consuming formula containing recombinant human insulin-like growth factor-I. Pediatric Research $\mathbf{4 2}$, $78-86$.

Huntington GB (1990) Energy metabolism in the digestive tract and liver of cattle: influence of physiological state and nutrition. Reproduction, Nutrition and Developement 30, 35-47.

Huntington GB \& Reynolds CK (1987) Oxygen consumption and metabolite flux of bovine portal-drained viscera and liver. Journal of Nutrition 117, 1167-1173.

Huntington GB \& Reynolds PJ (1986) Net absorption of glucose, L-lactate, volatile fatty acids, and nitrogenous compounds by bovine given abomasal infusions of starch or glucose. Journal of Dairy Science 69, 2428-2436.

Huntington GB, Reynolds PJ \& Tyrrell HF (1983) Net absorption and ruminal concentrations of metabolites in nonpregnant dry holstein cows before and after intraruminal acetic acid infusion. Journal of Dairy Science 66, 1901-1908.

Jansman AJM, Van Leeuwen P, Grala W \& Haaksma I (1997) Dynamics of amino acid absorption in pigs. In Proceedings of the VIIth International Symposium of Digestive Physiology in Pigs, EAAP Publication no. 88, pp. 316-321 [JP LaPlace, $\mathrm{C}$ Fevrier and A Barbeau, editors]. Saint-Malo, France: INRA.

Jensen BB (1998) The impact of feed additives on the microbial ecology of the gut in young pigs. Journal of Animal and Feed Sciences 7, 45-64.

Jeurissen SHM, Lewis F, Van der Klis JD, Mroz Z, Rebel JMJ \& Ter Huurne A (2002) Parameters and techniques to determine intestinal health of poultry as constituted by immunity, integrity and functionality. Current Issues in Intestinal Microbiology $\mathbf{3}$, $1-14$.

Johnson IT \& Gee JM (1981) Effect of gel-forming gums on the intestinal unstirred water layer and sugar transport in vitro. Gut 22, 332-335.

Kebreab E, France J, Agnew RE, Yan T, Dhanoa MS, Dijkstra J, Beever DE \& Reynolds CK (2003) Alternatives to linear analysis of energy balance data from lactating dairy cows. Journal of Dairy Science 86, 2904-2913.
Kelly D, Smyth JA \& McCracken KJ (1991) Digestive development in the early-weaned pig. 2. Effect of level of food intake on digestive enzyme activity during the immediate post-weaning period. British Journal of Nutrition $\mathbf{6 5}$, $181-188$

Klasing KC \& Calvert CC (1999) The care and feeding of an immune system: an analysis of lysine needs. In Proceedings of the 8th International Symposium on Protein Metabolism and Nutrition, EAAP Publication no. 96, pp. 253-264 [GE Lobley, A White and JC MacRae, editors]. Wageningen, The Netherlands: Wageningen Pers.

Krehbiel CR, Harmon DL \& Schnieder JE (1992) Effect of increasing ruminal butyrate in portal and hepatic nutrient fluxes in steers. Journal of Animal Science 70, 904-914.

Kreikemeier KK \& Harmon DL (1995) Abomasal glucose, maize starch and maize dextrin infusions in cattle: small intestine disappearance, net portal glucose flux and ileal oligosaccharide flow. British Journal of Nutrition 73, 763-772.

Kreikemeier KK, Harmon DL, Brandt RT, Avery TB \& Johnson DE (1991) Small intestine starch digestion in steers: effects of various levels of abomasal glucose, corn starch and corn dextrin infusion on small intestinal disappearance and net glucose absorption. Journal of Animal Science 69, 328-338.

Kristensen NB, Danfaer A \& Agergaard N (1996a) Diurnal patterns of ruminal concentrations and portal appearance rates of short-chain fatty acids in sheep fed a hay or a concentrate/straw diet in two meals daily. Acta Agriculturce Scandinavica 46, $227-238$

Kristensen NB, Danfær A \& Agergaard N (1998a) Absorption and metabolism of short-chain fatty acids in ruminants. Archives of Animal Nutrition 51, 165-175.

Kristensen NB, Danfær A \& Agergaard N (1998b) Short-chain fatty acids in sheep. Portal appearance rates following high intraruminal loads. Acta Agriculturce Scandinavica 48, 165-174.

Kristensen NB, Danfær A, Tetens V \& Agergaard N (1996b) Portal recovery of intraruminally infused short-chain fatty acids in sheep. Acta Agriculturce Scandinavica 46, 26-38.

Kristensen NB, Pierzynowski S \& Danfaer A (1999) Metabolism of $1,2,3,4-\mathrm{C}_{4}-\mathrm{D}-3-\mathrm{OH}$-butyrate by the portal-drained viscera: effects of intraruminal infusion of butyrate and propionate in sheep. South African Journal of Animal Science 29, 239-240.

Lamont JT (1992) Mucus: the front line of intestinal mucosal defense. Annals of New York Academy of Sciences 664, 190-201.

Langhout DJ (1998) The role of the intestinal flora as affected by nonstarch polysaccharides in broiler chiks. PhD Thesis, Wageningen Agricultural University, Wageningen, The Netherlands.

Lenis NP, Bikker P, Van der Meulen J, Van Diepen JThM, Bakker JGM \& Jongbloed AW (1996) Effect of dietary neutral detergent fiber on ileal digestibility and portal flux of nitrogen and amino acids and on nitrogen utilisation in growing pigs. Journal of Animal Science 74, 2687-2699.

Lindsay DB \& Reynolds CK (2005) Metabolism of the portaldrained viscera and liver. In Quantitative Aspects of Ruminant Digestion and Metabolism, 2nd ed., pp. 311-344 [J Dijkstra, JM Forbes and $\mathrm{J}$ France, editors]. Wallingford, UK: CAB International.

Lobley GE, Connell A, Milne E, Newman AM \& Ewing TA (1994) Protein synthesis in splanchnic tissues of sheep offered two levels of intake. British Journal of Nutrition 71, 3-12.

Lopez S, Hovell FDD, Dijkstra J \& France J (2003) Effects of volatile fatty acids supply on their absorption and on water kinetics in the rumen of sheep sustained by intragastric infusions. Journal of Animal Science 81, 2609-2616.

Lozano O, Theurer CB, Alio A, Huber JT, Delgado-Elorduy A, Cuneo P, DeYoung D, Sadik M \& Swingle RS (2000) Net absorption and hepatic metabolism of glucose, L-lactate, and volatile fatty acids by steers fed diets containing sorghum grain 
processed as dry-rolled or steam-flaked at different densities. Journal of Animal Science 78, 1364-1371.

Lupton JR \& Kurtz PP (1993) Relationship of colonic luminal short-chain fatty acids and $\mathrm{pH}$ to in vivo cell proliferation in rats. Journal of Nutrition 123, 1522-1530.

Maas JA, France J, Dijkstra J, Bannink A \& McBride BW (1998) Modelling amino acid uptake by the lactating bovine mammary gland. Journal of Dairy Science 81, 1724-1734.

McBride BW \& Kelly JM (1990) Energy cost of absorption and metabolism in the ruminant gastrointestinal tract and liver: a review. Journal of Animal Science 68, 2997-3010.

McCauley RD, Heel KA, Christiansen KJ \& Hall JC (1996) The effect of minimum luminal nutrition on bacterial translocation and atrophy of the jejunum during parenteral nutrition. Journal of Gastroenterology and Hepatology 11, 65-70.

MacDonald IA (1999) Aterio-venous differences to study macronutrient metabolism: introduction and overview. Proceedings of the Nutrition Society 58, 871-875.

McNurlan MA \& Garlick PJ (1980) Contribution of rat liver and gastrointestinal tract to whole-body protein synthesis in the rat. Biochemical Journal 186, 381-383.

Mantle M \& Allen A (1989) Gastrointestinal mucus. In Gastrointestinal Secretion, pp. 202-229 [JS Davidson, editor]. Cambridge, UK: Butterworth \& Co (Publishers) Ltd.

Maxwell FJ \& Stewart CS (1995) Microbiology of the gut and the role of probiotics. In The Neonatal Pig. Development and Survival, pp. 155-186 [MA Varley, editor]. Wallingford, UK: CAB International.

Milligan LP \& McBride BW (1985) Energy costs of ion pumping by animal tissues. Journal of Nutrition 115, 1374-1382.

Montalto M, Veneto G, Cuoco L, Cammarota G, Tursi A, Papa A, Fedeli G \& Gasbarrini G (1997) Intestinal permeability. Recenti Progressi in Medicina 88, 140-147.

Mroz Z, Koopmans S-J, Bannink A, Partanen K, Krasucki W, Øverland M \& Radcliffe S (2005) Carboxylic acids as bioregulators and gut growth promoters in non-ruminants. In Biology of the Intestine, pp. 81-133 [ $\mathrm{R}$ Mosenthin and $\mathrm{T}$ Zebrowska, editors]. Amsterdam, The Netherlands: Elsevier.

Mroz Z, Øverland M, Reese DE, Granli T, Kogut J \& Kjeldsen KC (2003) Duodeno-jejunal changes in acidity and concentrations of formate, lactate and minerals as affected by potassium diformate and formic acid in diets for young pigs. In Proceedings of the 9th International Symposium on Digestive Physiology in Pigs, pp. 180-182 [RO Ball, editor]. Banff, AB, Canada: University of Alberta.

Nabuurs MJA (1991) Etiologic and pathogenic studies on postweaning diarrhoea. $\mathrm{PhD}$ Thesis, State University of Utrecht, Utrecht, The Netherlands.

Nabuurs MJA (1997) Weaning piglets as a model for studying pathophysiology of diarrhoea. The Veterinary Quarterly 20, S42-S45.

Nieto R \& Lobley GE (1999) Integration of protein metabolism within the whole body and between organs. In Proceedings of the 8th International Symposium on Protein Metabolism and Nutrition, EAAP Publication no. 96, pp. 69-99 [GE Lobley, A White and JC MacRae, editors]. Wageningen, The Netherlands: Wageningen Pers.

Nozière P, Martin C, Rémond D, Kristensen NB, Bernard R \& Doreau M (2000) Effect of composition of ruminally-infused short-chain fatty acids on net fluxes of nutrients across portaldrained viscera in underfed ewes. British Journal of Nutrition 83, 521-531.

Pabst R \& Rothkötter H J (1998) The morphological and functional basis of the immune function of the intestinal wall: a barrier function in contrast to the absorption of nutrients. Proceedings of the Society of Nutritional Physiology 7, 13-22.
Parker DS (1990) Manipulation of the functional activity of the gut by dietary and other means (antibiotics/probiotics) in ruminants. Journal of Nutrition 120, 639-648.

Partanen KH \& Mroz Z (1999) Organic acids for performance enhancement in pig diets. Nutrition Research Reviews 12, $117-145$.

Perozzi G, Barila D, Murgia CH, Kelly D, Begbie R \& King TP (1993) Expression of differentiated functions in the developing porcine small intestine. Journal of Nutritional Biochemistry 4, 699-705.

Pluske JR, Williams IH \& Aherne FX (1996) Maintenance of villous height and crypt depth in piglets by providing continuous nutrition after weaning. Animal Science 62, 131-144.

Pratt VC, Tappenden KA, McBurney MI \& Field CJ (1996) Shortchain fatty acid-supplemented total parenteral nutrition improves nonspecific immunity after intestinal resection in rats. Journal of Parenteral and Enteral Nutrition 20, 264-271.

Rechkemmer G, Gabel G, Dierneas L, Sehested J, Moller PD \& Von Engelhardt W (1995) Transport of short-chain fatty acids in the forestomach and hindgut. In Ruminant Physiology: Digestion, Metabolism, Growth and Reproduction, pp. 93-113 [W Von Engelhardt, S Leonhard-Marek, G Breves and D Gieseke, editors]. Stuttgart, Germany: Ferdinand Enke Verlag.

Reeds PJ, Burrin DG, Stoll B \& Van Goudoever JB (1999) Consequences and regulation of gut metabolism. In Proceedings of the 8th International Symposium on Protein Metabolism and Nutrition, EAAP Publication no. 96, pp. 127-153 [GE Lobley, A White and JC MacRae, editors]. Wageningen, The Netherlands: Wageningen Pers.

Reeds PJ, Fjeld CR \& Jahoor F (1994) Do the differences between amino acid compositions of acute-phase and muscle proteins have a bearing on nitrogen loss in traumatic states? Journal of Nutrition 124, 906-910.

Rémond D, Ortigues I \& Jouany J-P (1995) Energy substrates for the rumen epithelium. Proceedings of the Nutrition Society 54, 95-105.

Rérat A (1988) Resultats experimentaux sur la physiologie digestive et l'absorption en relation avec la nutrition et le metabolisme des acides amines (Experimental results on digestive physiology and absorption in relation to nutrition and the metabolism of amino acids). In Tagingsbericht, Tagung zur Verleihung des Roche Research Prize for Animal Nutrition. Zurich, Switzerland: ETH Zurich.

Rérat A (1996) Influence of the nature of carbohydrate intake on the absorption chronology of reducing sugars and volatile fatty acids in the pig. Reproduction Nutrition and Development 36, $3-19$.

Rérat A, Jung J \& Kandé J (1988a) Absorption kinetics of dietary hydrolysis products in conscious pigs given diets with different amounts of fish protein. 2. Individual amino acids. British Journal of Nutrition 60, 105-120.

Rérat A, Simoes Nunes C, Mendy F \& Roger L (1988b) Amino acid absorption and production of pancreatic hormones in nonanaesthetized pigs after duodenal infusions of a milk enzymic hydrolysate or of free amino acids. British Journal of Nutrition 60, $121-136$.

Rérat A, Simoes-Nunes C, Mendy F, Vaissade P \& Vaugelade P (1992) Splanchnic fluxes of amino acids after duodenal infusion of carbohydrate solutions containing free amino acids or oligopeptides in non-anaesthetized pigs. British Journal of Nutrition 68, 111-138.

Rérat A, Vaissade P \& Vaugelade P (1984a) Absorption kinetics of some carbohydrates in conscious pigs. 1. Qualitative aspects. British Journal of Nutrition 51, 505-515.

Rérat A, Vaissade P \& Vaugelade P (1984b) Absorption kinetics of some carbohydrates in conscious pigs. 2. Quantitative aspects. British Journal of Nutrition 51, 517-529. 
Rérat A, Vaissade P \& Vaugelade P (1991) Comparative digestion of maltitol and maltose in unanesthetized pigs. Journal of Nutrition 121, 737-744.

Reynolds CK \& Huntington GB (1988a) Partition of portal-drained visceral net flux in beef steers. 1. Blood flow and net flux of oxygen, glucose and nitrogenous compounds across stomach and post-stomach tissues. British Journal of Nutrition 60, $539-551$

Reynolds CK \& Huntington GB (1988b) Partition of portal-drained visceral net flux in beef steers. 2. Net flux of volatile fatty acids, D- $\beta$-hydroxybutyrate and L-latate across stomach and post-stomach tissues. British Journal of Nutrition 60, 553-562.

Reynolds CK, Huntington GB, Tyrrell HF \& Reynolds PJ (1988) Net portal-drained visceral and hepatic metabolism of glucose, L-lactate, and nitrogenous compounds in lactating holstein cows. Journal of Dairy Science 71, 1803-1812.

Reynolds CK, Sutton JD \& Beever DE (1997) Effects of feeding starch to dairy cows on nutrient availability and production. In Recent Advances in Animal Nutrition. Proceedings of the 30th University of Nottingham Conference for Feed Manufacturers, pp. 105-134 [PC Garnsworthy and J Wiseman, editors]. Nottingham, UK: Nottingham University Press.

Rijnen MMJA (2003) Energetic utilisation of dietary fiber in pigs. PhD Thesis, Wageningen University, Wageningen, The Netherlands.

Rijnen MMJA, Dekker RA, Bakker GCM, Verstegen MWA \& Schrama JW (2001) Effects of dietary fermentable carbohydrates on the empty weights of the gastrointestinal tract in growing pigs. In Proceedings of the 8th Symposium of Digestive Physiology of Pigs, pp. 17-20 [JE Lindberg and B Ogle, editors]. Wallingford, UK: CAB International.

Sakata T (1987) Stimulatory effect of short-chain fatty acids on epithelial cell proliferation in the rat intestine: a possible explanation for trophic effects of fermentable fibre, gut microbes and luminal trophic factors. British Journal of Nutrition 58, 95-103.

Sakata T, Hikosaka K, Shiomura Y \& Tamate H (1980) Stimulatory effect of insulin on ruminal epithelium cell mitosis in adult sheep. British Journal of Nutrition 44, 325-331.

Sangild PT (2001) Transitions in the life of the gut at birth. In Proceedings of the 8th Symposium Digestive Physiology of Pigs, pp. 3-17 [EJ Lindberg and B Ogle, editors]. Wallingford, UK: CAB International.

Sangild PT, Silver M, Schmidt M \& Fowden AL (1996) The perinatal pig in pediatric gastroenterology. In Advances in Swine in Biomedical Research, vol. 2, pp. 745-756 [ME Tumbleson and LB Schook, editors]. Wallingford, UK: CAB International.

Seal CJ \& Parker DS (1994) Effects of intraruminal propionic acid infusion on metabolism of mesenteric- and portal-drained viscera in growing steers fed a forage diet: I. Volatile fatty acids, glucose and lactate. Journal of Animal Science 72, $1325-1334$.

Shanahan F (1994) The intestinal immune system. In Physiology of the Gastrointestinal Tract, 3rd ed., pp. 643-684 [LR Johnson, DH Alpers, J Christensen, ED Jacobson and JH Walsh, editors]. New York: Raven Press.

Shen Z, Seyfert H-M, Löhrke B, et al, (2004) An energy-rich diet causes rumen papillae proliferation associated with more IGF type 1 receptors and increased plasma IGF- 1 concentrations in young goats. Journal of Nutrition 134, 11-17.

Simon O (1989) Metabolism of proteins and amino acids. In Protein Metabolism in Farm Animals, pp. 273-366 [H-D Bock, BO Eggum, AG Low, O Simon and T Zebrowska, editors]. Berlin and Oxford: VEB Duetscher Landwirtschaftsverlage and Oxford University Press.
Smith NE \& Baldwin RL (1974) Effects of breed, pregnancy, and lactation on weights of organs and tissues in dairy cattle. Journal of Dairy Science 57, 1055-1060.

Smith RJ \& Wilmore DW (1990) Glutamine nutrition and requirements. Journal of Parenteral and Enteral Nutrition 14, 94S-99S.

Stoll B \& Burrin DG (2006) Measuring splanchnic amino acid metabolism in vivo using stable isotope tracers. Journal of Animal Science 84, E60-E72.

Stoll B, Burrin DG, Henry J, Yu H, Jahoor F \& Reeds PJ (1999) Substrate oxidation by the portal drained viscera of fed piglets. American Journal of Physiology 277, E168-E175.

Stoll B, Henry J, Reeds PJ, Yu H, Jahoor F \& Burrin DG (1998) Catabolism dominates the first-pass intestinal metabolism of dietary essential amino acids in milk protein-fed piglets. Journal of Nutrition 128, 606-614.

Summers M, McBride BW \& Milligan LP (1988) Components of basal energy expenditure. In Aspects of Digestive Physiology in Ruminants, pp. 257-285 [A Dobson and MJ Dobson, editors]. Ithaca, NY: Comstock Publishing Associates.

Van Beers-Schreurs HMG (1996) The changes in the function of the large intestine of weaned pigs. PhD Thesis, State Unversity of Utrecht, Utrecht, The Netherlands.

Van der Meulen J, Bakker GCM, Bakker JGM, De Visser H, Jongbloed AW \& Everts H (1997a) Effect of resistant starch on net portal-drained viscera flux of glucose, volatile fatty acids, urea, and ammonia in growing pigs. Journal of Animal Science 75, 2697-2704.

Van der Meulen J, Bakker JG, Smits B \& De Visser H (1997b) Effects of source of starch on net portal flux of glucose, lactate, volatile fatty acids and amino acids in the pig. British Journal of Nutrition 78, 533-544.

Van der Meulen J \& Jansman AJM (1997) Nitrogen metabolism in gastrointestinal tissue of the pig. Proceedings of the Nutrition Society 56, 535-545.

Van der Meulen J \& Smits B (1997) Digestion and portal appearance of glucose of different sources of non-resistant starch. In Digestive Physiology in Pigs. Proceedings of the VIIth International Symposium on Digestive Physiology in Pigs, pp. 279-282 [J-P Laplace, C Février and A Barbeau, editors]. Saint-Malo, France: INRA.

Van Goudoever JB, Stoll B, Henry JF, Burrin DG \& Reeds PJ (2000) Adaptive regulation of intestinal lysine metabolism. Proceedings of the National Academy of Science USA 97, $11620-11625$.

Van Leeuwen P \& Versantvoort CHM (1999) Functional histology of the small intestinal mucosa in livestock production animals. In Nutrition and Gastrointestinal Physiology - Today and Tomorrow, pp. 9-21 [AJM Jansman and J Huisman, editors]. Wageningen, The Netherlands: TNO.

Van Soest PJ (1994) Nutritional Ecology of the Ruminant, 2nd ed. Ithaca, NY: Cornell University Press.

Verdonk H (2006) Nutritional strategy affects gut integrity in eaned piglets. PhD Thesis, Wageningen University, Wageningen, The Netherlands.

Vinardell MP (1990) Mutual inhibition of sugars and amino acid intestinal absorption. Comparative Biochemistry and Physiology 95A, 17-21.

Waheed AA, Yasuzumi F \& Gupta PD (1998) Lipid and fatty acid composition of brush border membrane of rat intestine during starvation. Lipids 33, 1093-1097.

Webb KE \& Bergman EN (1991) Amino acid and peptide absorption and transport across the intestine. In Physiological Aspects of Digestion and Metabolism in Ruminants. Proceedings of the 7th International Symposium on Ruminant Physiology, pp. 111-128 [T Tsuda, Y Sasaki and R Kawashima, editors]. San Diego, CA: Academic Press. 
Windmueller HG \& Spaeth AE (1974) Uptake and metabolism of plasma glutamine by the small intestine. Journal of Biological Chemistry 249, 5070-5079.

Windmueller HG \& Spaeth AE (1975) Intestinal metabolism of glutamine and glutamate from the lumen as compared to glutamine from blood. Archives of Biochemistry and Biophysics 171, 662-672.

Windmueller HG \& Spaeth AE (1976) Metabolism of absorbed aspartate, asparagine, and arginine by the rat small intestine in vivo. Archives of Biochemistry and Biophysics 175, 670-676.

Windmueller HG \& Spaeth AE (1980) Respiratory fuels and nitrogen metabolism in vivo in the small intestine of fed rats. Quantitative importance of glutamine, glutamate, and aspartate. Journal of Biological Chemistry 255, 107-112.

Wu G (1998) Intestinal mucosal amino acid catabolism. Journal of Nutrition 128, 1249-1252.
Wu G, Borbolla AG \& Kanbe DA (1994) The uptake of glutamine and release of arginine, citrulline and proline by the small intestine of developing pigs. Journal of Nutrition 124, 2437-2444.

Yen JT, Nienaber JA, Hill DA \& Pond WG (1989) Oxygen consumption by portal vein-drained organs and by whole animal in conscious growing swine. Proceedings of the Society of Experimental Biology and Medicine 190, 393-398.

Yu YM, Burke JF, Vogt JA, Chambers L \& Young VR (1992) Splanchnic and whole body $\mathrm{L}-\left[{ }^{1-13} \mathrm{C},{ }^{15} \mathrm{~N}\right]$ leucine kinetics in relation to enteral and parenteral amino acid supply. American Journal of Physiology 262, E687-E694.

Zambell KL, Fitch MD \& Fleming SE (2003) Acetate and butyrate are the major substrates for de novo lipogenesis in rat colonic epithelial cells. Journal of Nutrition 133, 3509-3515. 